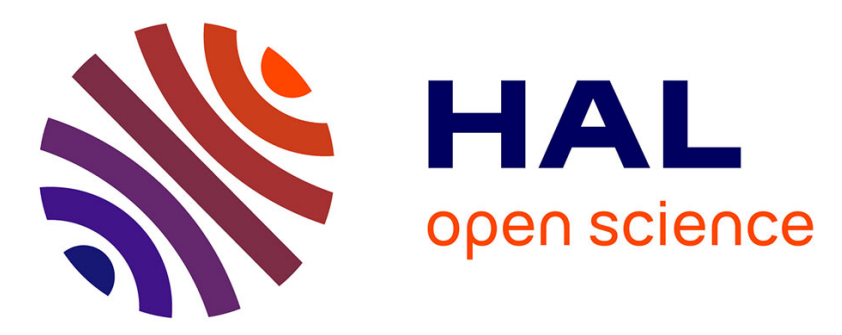

\title{
Computer-Aided Decision for Human Task Allocation with Mono and Multi-Performance Evaluation
}

Meziane Bennour, Didier Crestani, Olivier Crespo, François Prunet

\section{To cite this version:}

Meziane Bennour, Didier Crestani, Olivier Crespo, François Prunet. Computer-Aided Decision for Human Task Allocation with Mono and Multi-Performance Evaluation. International Journal of Production Research, 2005, 43 (21), pp.4559-4588. 10.1080/00207540500124579 • lirmm-00105309

\section{HAL Id: lirmm-00105309 \\ https://hal-lirmm.ccsd.cnrs.fr/lirmm-00105309}

Submitted on 11 Oct 2006

HAL is a multi-disciplinary open access archive for the deposit and dissemination of scientific research documents, whether they are published or not. The documents may come from teaching and research institutions in France or abroad, or from public or private research centers.
L'archive ouverte pluridisciplinaire HAL, est destinée au dépôt et à la diffusion de documents scientifiques de niveau recherche, publiés ou non, émanant des établissements d'enseignement et de recherche français ou étrangers, des laboratoires publics ou privés. 


\title{
Computer-aided decision for human task allocation with mono- and multi-performance evaluation
}

\author{
M. BENNOUR, D. CRESTANI*, O. CRESPO and F. PRUNET \\ Laboratoire d'Informatique, de Robotique et de Microélectronique de Montpellier (LIRMM), \\ 161, rue Ada, F-34392 Montpellier cedex 5, France
}

(Received January 2005)

\begin{abstract}
An efficient Binary Search-based approach used to determine the sets of human resources allowing one to reach, for an enterprise process, a given performance level is presented. It is based on an enterprise process performance methodology integrating human skill influence. In a first step, this approach is compared with algorithms such as Hybrid Taboo-Descent, Simulated Annealing and Knapsack algorithms for different performance points of view (temporal, financial, quality oriented) on limited and large complexity examples. In a second step, this approach is generalized to integrate simultaneously several viewpoints.
\end{abstract}

Keywords: Human resource allocation; Performance estimation; Binary Search Algorithm

\section{Introduction}

Production planning and scheduling have been intensively studied since the 1950s. The research areas involve many disciplines such as operational research or business and management sciences. From the 1980s, the development of information technologies has minimized the real impact of human factors on process performance. However, it is now admitted that above the technological aspects, human and organizational factors largely influence productivity. Unfortunately, due to the difficulties in modelling human behaviour and cognitive capacities, few works are currently available on human skill integration for task allocation. Therefore, it is useful for a human scheduler to develop a computer-aided decision approach allowing them to identify quickly and efficiently the relevant resource assignments alternatives (McKay et al. 1992, McCarthy et al. 2001).

The work proposed in this paper focused on the description and evaluation of a Binary Search-based allocation algorithm. This study relies on a process performance estimation approach integrating the influence of human skills (Covès 2000, Covès et al. 2000).

First, we note the complexity of human task allocation by explaining the main constraints that must be taken into account. We then summarize the performance estimation methodology, which is worked out with an industrial partner, and

*Corresponding author. Email: crestani@lirmm.fr 
support the human resource allocation approach proposed. In a first step, the basic Binary Search Algorithm (BSA) is explained. Its efficiency is then compared, from different performance points of view (temporal or financial or quality oriented), with more approaches (Hybrid Taboo-Descent, Simulated Annealing and efficient Knapsack algorithms), on a limited or large-scale examples. In a second step, before concluding, the proposed allocation approach is generalized to integrate simultaneously several points of view (temporal and financial and quality oriented) in order to address real problems.

\section{Human allocation: many constraints to integrate}

Human management problems depend on the timed term within which the allocation decision must be taken (Franchini et al. 1998). The long-term or strategic view allows one to evaluate different management policies (Lengnick-Hall and Lengnick-Hall 1988, Wright and Snell 1991). The medium-term view looks to define the human resource requirements planning. In this case, the main objective is to cover optimally the workload with the available resources while satisfying organizational, managerial and resource constraints (Kusiak and Chen 1988, Franchini et al. 2001, Vairaktarakis et al. 2002). Finally, the short-term view permits one to schedule and allocate resources according to more operational constraints (Chen 1995, Beaumont 1997, Jia 1998, Hung 1999, Franchini et al. 2001, Mosheiov 2001).

For human allocation, the human skills constraints represent a first and important class of constraints to be satisfied for the trades involved to realize the tasks of a process activity. In fact, for a considered activity, the workers can be affected only if they can carry out the working task. For the considered task, this constraint leads one to define and characterize the needed skills. However, the workers' skills must be known and evaluated. In summary, human skills must satisfy working needs. This obvious constraint is clearly pointed out in enterprise models such as CIMOSA (AMICE 1993), which defines functional entities having their capability set from the resource point of view and an enterprise activity with their own capability set of required capabilities from a functional point of view. The concept of a human role model is also developed in PERA (Williams 1994) and GERAM (Williams 1995) enterprise architectures. More recently, the concept of the person role is used in the Unified Enterprise Modelling Language project (UEML 2003).

Moreover, another class of constraints deals with the quantitative constraints concerning the workforce that defines the number of human workers needed by trade to realize a task. This constraint hardly increases the complexity of the allocation process. It is usually taken into account to formulate the general workers scheduling problem (Soubeiga 2003) such as in Dantzig's (1954) formulation where a coverage constraint is introduced (the number of needed employees).

The human availability constraints cover many aspects such as social, industrial and legislative rules in a production environment that must be satisfied. Holidays, days off, legal working limits and company rules must be integrated. The days-off scheduling (Alfares 2000) intends to specify work and no work days. Shift scheduling (Aykin 2000, Narasimhan 2000) focuses on determining a set of work schedules across a daily planning horizon. Finally, tour scheduling (Brusco and Jacobs 2000, 
Bard et al. 2003) considers days off and shift scheduling for a weekly planning horizon.

Performance constraints (or objective) must also be verified for an enterprise process. Many studies have demonstrated the importance of human resource management for performance (Guest 1997, McEwan and Sackett 1998). Among all of the studied objectives (profitability, productivity, training cost, etc.), the main generic constraint which is imposed in a production environment is the time constraint (job duration, release and due dates). An important part of the literature focuses on this temporal point of view. However, the enterprises cover other important performance facets such as the financial and quality points of view which are more rarely taken into account during allocation studies.

In summary, the main classes of constraints that must be addressed considering the human allocation task problem concern workers' availability, task-skill satisfaction, workforce evaluation and performance generation. The human allocation task covers all the decision levels and integrates a very large amount of constraints that are not presently simultaneously addressed in research studies. Moreover, few research studies integrate the human aspect in production scheduling and resource allocation (Franchini et al. 2001, Tchommo et al. 2003).

In the following, we consider the problem of human allocation for an enterprise process behaviour that can be seen as a tasks schedule. This paper does not directly take into account human skills and availability constraints. It focuses on the satisfaction of mono- and multi-performance constraints by using a skill-guided performance estimation methodology.

\section{Used performance estimation methodology: a summary}

The proposed methodology intends to integrate human skills influence for performance estimation. It has been developed in a research project from the proposition of our industrial partner. In this project, based on industrial expertise, we have proposed to link performance estimation to human skills by using empirical but good sense laws (discrete law, linear law, bar chart, etc.) (Covès 2000, Covès et al. 2000). In addition to individual aspects, this approach tries to integrate collective behaviours by considering, for example, managerial capacities or communication abilities.

In fact, if we consider that an activity $i$ is characterized for a given point of view $v$ (temporal, financial or quality oriented), by its nominal performance $\mathrm{NomP}_{i v}$, these laws allow one to modulate the proportion of nominal performance associated to a performance criteria $k$ (skill) by computing a modulation coefficient $\gamma_{k v}$. The importance of each skill $(k)$ for the execution of the activity is characterized by a weighted coefficient $a_{i k}$ determined by an expert. Then the activity performance estimation $\left(\mathrm{AP}_{i v}\right)$ can be explained by equation (1).

$$
\mathrm{AP}_{i v}=\sum_{k} \alpha_{i k} \cdot \mathrm{NomP}_{i v}+\gamma_{i k} \cdot \alpha_{i k} \cdot \mathrm{NomP}_{i v}=\sum_{k}\left(1+\gamma_{i k} \cdot \alpha_{i k}\right) \cdot \operatorname{NomP}_{i v}
$$

The implicit use of laws has been previously proposed to link personal abilities and activity performance. For example, the efficiency of a worker is characterized by a coefficient in Bobrowski and Park (1993) and used to affect the workers to the tasks. 
Furthermore, some researches integrate a learning effect (Eckstein and Rohleder 1998, Kher et al. 1999) to estimate the duration of the tasks. Other sciences such as political economy, for example (Parsons 1972), use formal laws to model humans at work. These previous works employ a limited model of people's skills. Therefore, the originality of our approach in a manufacturing context, based upon our industrial partner expertise, is to propose several class of skill-oriented laws and try to aggregate their influence on activity performance by using weighted coefficients. This kind of modulation, where the relative importance of a class of skills to a considered task is evaluated is also proposed by Franchini (2000) and Norman et al. (2002). However, in these studies, the obtained coefficients are not directly used to estimate performance. In our approach, a multi-criteria method such as AHP (Saaty 1980) based on industrial interviews can be used, for example, to set the value of the different weights.

To estimate the performance reached on an activity output, for a process behaviour $\sigma$ representing the sequence of realized activities, three performance classes have been distinguished:

- Activity performance $\left(\mathrm{AP}_{i}\right)$ previously defined that estimates the performance of a particular activity $\mathrm{A}_{i}$.

- Upstream performance $\left(\mathrm{UP}_{i}\right)$ that corresponds to the performance of the part of the process which is executed before the activity $\mathrm{A}_{i}$ in the sequence $\sigma$.

- Feedback performance $\left(\mathrm{FP}_{i}\right)$ that is introduced to take into account, for some points of view, the existence of iteration into $\sigma$ on a fan-in activity.

Finally, the output performance $\left(\mathrm{OP}_{i}\right)$ of an activity $i$, for a performance point of view $v$, can be estimated with equation (2):

$$
\mathrm{OP}_{i v}=\mathrm{AP}_{i v}+\mathrm{UP}_{i v}+\mathrm{FP}_{i v}
$$

In the following, we will illustrate the implementation of this performance estimation methodology for an enterprise process from temporal-, financial- and qualityoriented points of view.

\section{Objectives of the computer-aided decision methodology}

The main goal of the proposed approach is to provide to the industrial user (the human scheduler, for example) a tool that can quickly determine the set of workers allowing one to reach one or several performance objectives (PO) for a considered enterprise process. These objectives depend on the chosen point of view. Generally the duration of the process must be less or equal than an objective $\mathrm{PO}_{\mathrm{T}}$, its financial cost must be less or equal than $\mathrm{PO}_{\mathrm{F}}$ and the quality greater or equal than $\mathrm{PO}_{\mathrm{Q}}$.

Even if the allocated actors satisfy the skill and availability constraints, the chosen association choices for allocation largely influence the final process performance. It is clear that the efficiencies of a novice and an expert worker are not equivalent. This obvious fact has been pointed out by several studies using skill levels (Franchini 2000, Drejer 2001, Norman et al. 2002) and largely influences the duration of a task execution and then its associated cost. Moreover, the capacity of several human to work together is also a very important parameter. It is well known that at the operational level, due to this social aspect, the ability of a worker to lead 


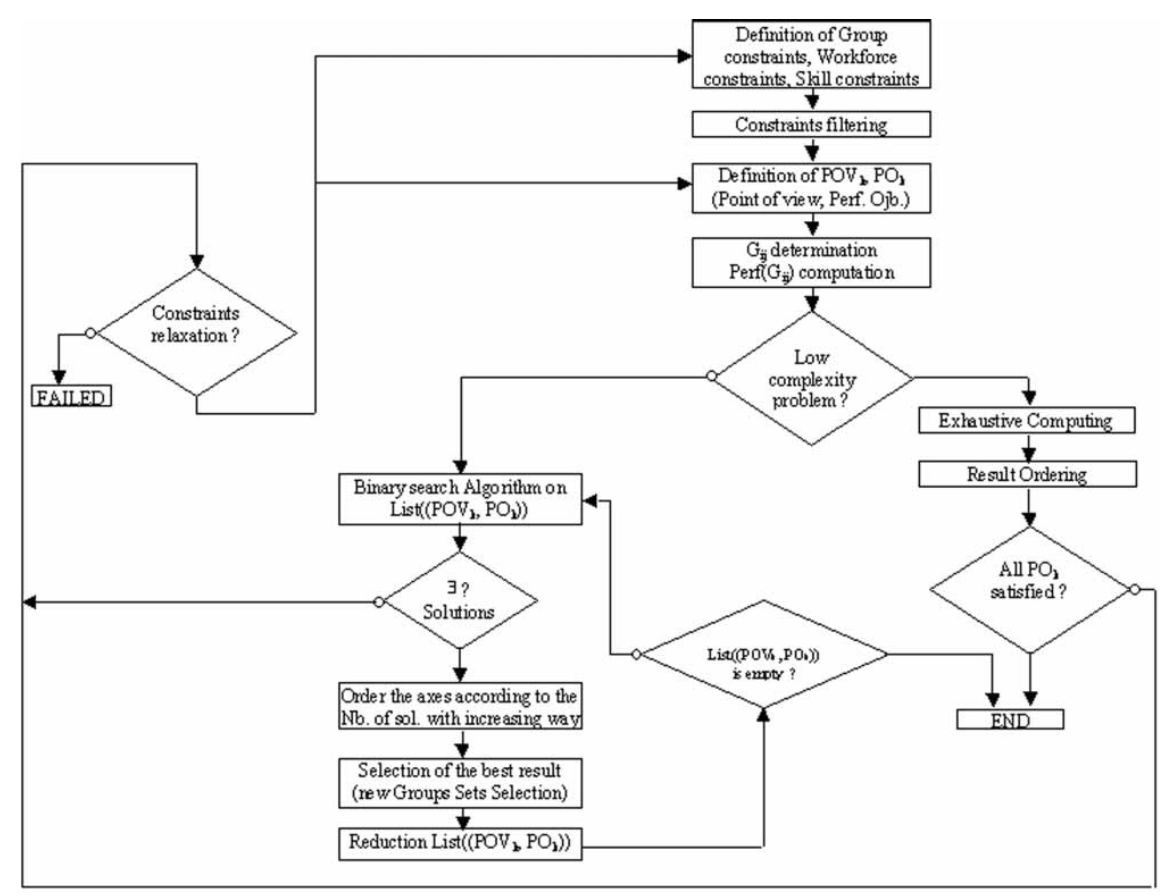

Figure 1. Global allocation process.

a team or to support collective working can induce a very important gradient for a task dynamic and its associated cost. This influence of humans is studied in worker team-oriented papers (Kolbe 1994, Kembel 1996, Medsker and Fry 1997). Therefore, the choice of the allocated actors is not neutral even if any of them looks like it will be adapted to the working task. The previous performance estimation methodology, which is based on skills modelling including knowledge, know-how and also integrates the social aspect, can then guide efficiently the choice of the workers during the choice process.

Figure 1 summarizes the main steps of the proposed approach. For each activity, the user initially defines the workforce, skill and group constraints. The group constraint fixes the initial sets of actors (ISA) within the choice must be done. For example, for a given task of an activity, the worker must belong to the production team of the company. Then, a filtering step allows to reduce the different ISA by taking into account the worker's skills and availability. For an activity, the final sets of actors (FSA) obtained after filtering contains the list of workers that are available and possess the minimal skills to do the tasks. Then, for each activity $i$ of a process, $\mathrm{NC}_{i}$ groups $\mathrm{G}_{i j}\left(1 \leq j \leq \mathrm{NC}_{i}\right)$ of a set of potential human resources are built. $\mathrm{G}_{i j}$ corresponds in fact to a group of workers belonging to the activity FSA and satisfying the workforce constraint defined. It is now possible to compute for each activity, and for each chosen performance point of view, the corresponding activity performance generated by a possible allocation $\mathrm{G}_{i j}$.

From this point, which constitutes the real starting point of our problem, the complexity of the allocation problem can be easily determined. It corresponds to the 
exhaustive exploration of all the allocation possibilities. In the worst case, it can be explained by equation (3):

$$
\text { Allocation_Possibilities }=\prod_{k} N C_{k}
$$

where $k$ is the number of activities. From this fact, two cases can be considered. (1) Either the combinatorial complexity is low and an exhaustive simulation of all the allocation possibilities allows one to find quickly all the possible allocations satisfying the imposed PO. (2) Or non-exact and efficient approaches depending on monoor multi-objectives satisfaction must be used. To deal with large complexity problem, we have developed a heuristic allocation approach based on the used performance estimation methodology properties and on BSA principles. The mechanism allowing one to decide the class of used algorithm (non-exact or exhaustive) will be detailed below. Moreover, the multi-objectives approach will be developed in the second part of this paper.

We now detail the proposed human allocation approach. For this problem, the enterprise process and its corresponding behaviour can be seen as a given schedule of the tasks (activities) that must be realized to achieve the enterprise's objectives. It is a schedule since the sequential order or the concurrency of the tasks are completely defined. However, the duration of the different tasks and of the process is not known. The goal of the allocation approach is then to work out precisely which workers can be used to reach one PO or more. The studied problem of performance goals achievement can be seen as a Knapsack Problem, which is well known to be NP-hard (Pisinger 1995a, b, Kulanoot 2000). Due to the complexity of the problem, this paper also focuses on heuristic approaches to find the allocation solutions.

\section{Principles of the Binary Search Algorithm}

\subsection{Local and global context}

Once the FSA is defined, the performance estimation methodology can compute locally, for each activity $i$, the corresponding performance contribution associated to the $\mathrm{NC}_{i}$ groups of actors $G_{i j}$. It is then easy to order locally, for an activity, the found performance from the lower to the upper. Figure 2 shows for three activities an example of the ordered list of performance. Each value corresponds to the performance of a set of actors satisfying the skills, workforce and availability constraints.

The global enterprise process performance is obtained by adding all the activity performances (one by activity). As we will see below, the merging laws (added or max laws) preserve globally the local order relation for the used performance estimation approach.

It is well known that a BSA is an efficient approach to find an element in an ordered list of $N$ items by repeatedly dividing the search interval in half. Its complexity in $O(\ln N)$ is low. Therefore, the basic idea of the proposed approach is to combine the capacity and property of the performance estimation approach with the efficiency of a BSA to compute quickly a set of actors satisfying the PO. 


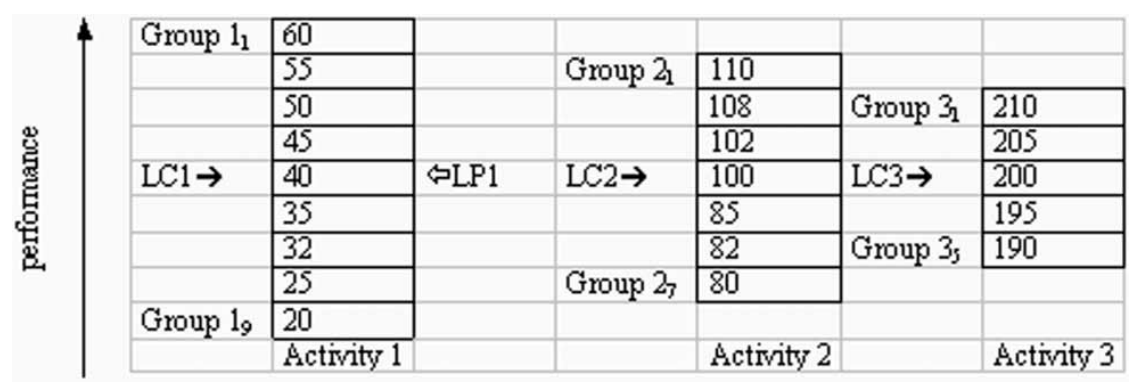

Figure 2. Example of performance configuration (in performance unit).

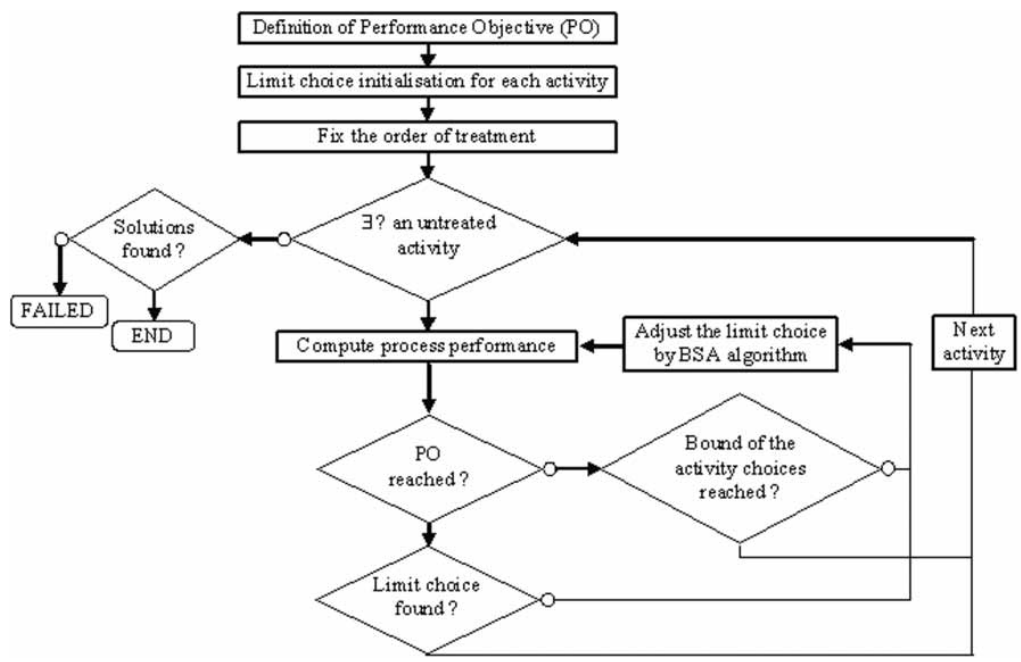

Figure 3. Binary search based algorithm (BSA).

It can be done by introducing for an activity $i$ the concept of limit choice $\left(\mathrm{LC}_{i}\right)$ that corresponds itself to a limit performance $\left(\mathrm{LP}_{i}\right)$. The limit choice (figure 2 ) splits the set of ordered choices into two parts. A set of choices with a performance higher than $\mathrm{LP}_{i}$, and a set of choices with a performance less or equal than $\mathrm{LP}_{i}$. Now globally for an enterprise process, since the performance merging laws maintain the order relation, the composition of all the activities limit choice allows one to conclude on the satisfaction or not of the process PO $(<,>$, etc.), in only one simulation, for an important number of actors allocation possibilities.

For example, in figure 2, if the merging law is the addition, the position of the three limit choices leads to a performance of 340 in performance unit.

\subsection{Proposed algorithm}

The basic and simplified algorithm of the BSA is presented in figure 3. It initially fixes the limit choice of each activity and globally computes the corresponding process performance. These limit choices are then modified, one activity at a time, by using a local BSA, in order to reach the PO at best. 
For example for the figure 2, a set of actors allowing to reach a $\mathrm{PO} \leq 354$ is computed with this algorithm in 17 simulations. The final limit choices (LC1, LC2, LC3) are $(50,102,200)$ correspond to the determination of $7 * 5 * 3=105$ different allocation solutions.

\subsection{Heuristic for the activities treatment}

However, once the initial limit choices are fixed, each local limit choice is adjusted successively without changing the value of the others. Therefore, the order of treatment of the different activities is not neutral. It is fixed by a heuristic. It uses a multi-criteria function that takes into account the performance mean, performance gradient and number of local choices $\mathrm{NC}_{i}$ for each activity. We consider first the activities with an important mean, few choices and little performance gradient. With this heuristic, we hope to fix quickly the limit choice for activities with much influence on the performance (mean), a limited impact (gradient) and few possible choices.

Using this heuristic for the figure 2 example leads the BSA first to treat activity 3 , then activity 2 and finally activity 1 . For the previous $\mathrm{PO} \leq 354$, the final limit choices (LC3, LC2, LC1) are $(210,102,40)$. They are found in simulations and correspond to the determination of $5 * 5 * 5=125$ different allocation solutions. This result is better than the previous one proposed above.

\subsection{Backtrack to enhance algorithm efficiency}

With the basic BSA, the final limit choice of an activity cannot be reconsidered once this activity has been treated. However, it can be interesting to backtrack (BSA_BK algorithm) if the first solution allowing one to satisfy the PO is only found after having considered the $k$ first activities. In this case, their associated limit choices are necessarily fixed to the upper or lower activity performance limit allowing to satisfy at best the PO.

Therefore, these $k$ activities are treated again and can generate a new limit choice position. This situation can allow one to detect more solutions than the basic BSA algorithm, but it needs more simulations. Consider, for example, the example in figure 2 for an objective of performance $\mathrm{PO} \leq 300$. The proposed heuristic finds the solution $(\mathrm{LC} 3, \mathrm{LC} 2, \mathrm{LC} 1)=(190,80,25)$ and it corresponds to only $1 * 1 * 2=2$ solutions of affectation computed in eight simulations. The backtrack mechanism generates the following new final limit choices $(\mathrm{LC} 3, \mathrm{LC} 2, \mathrm{LC} 1)=(190,85,25)$ corresponding to $1 * 3 * 2=6$ solutions. Therefore, in this example, the backtrack algorithm permits one to found three times more solutions than the basic BSA one. However, it needs 16 and then eight simulations more than without backtrack.

\section{Experimentation methodology}

\subsection{Description of the test examples}

To estimate the efficiency of the approach from different performance points of view (temporal, financial and quality oriented), two classes of examples have been used. 


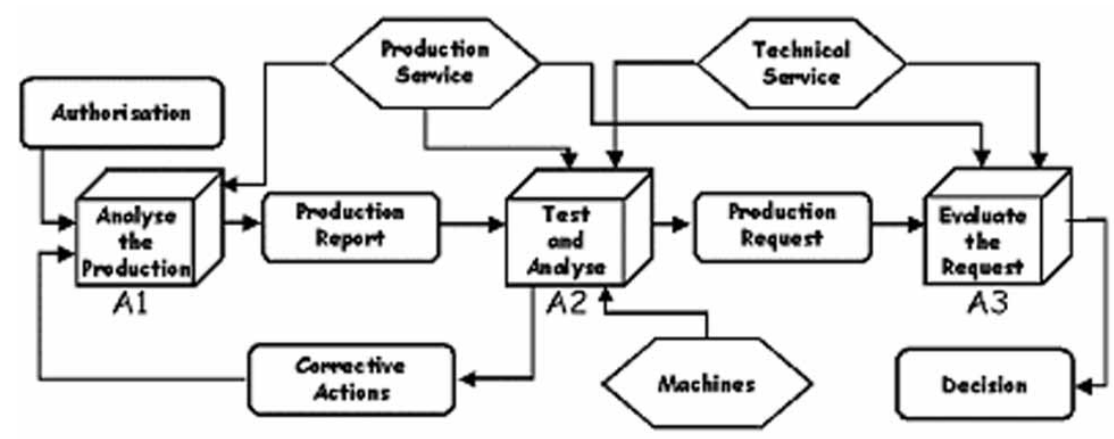

Figure 4. Production authorization process (PAP).

Table 1. Total number of possible allocations for exhaustive simulation.

\begin{tabular}{|c|c|c|c|c|c|c|}
\hline \multirow[b]{3}{*}{ Service } & \multicolumn{5}{|c|}{ Activity } & \multirow{3}{*}{$\begin{array}{c}\begin{array}{c}\text { Configuration } \\
\text { number }\end{array} \\
\Pi \text { config. }\end{array}$} \\
\hline & \multirow{2}{*}{$\frac{\mathrm{Al}}{\text { Prod }}$} & \multicolumn{2}{|c|}{$\mathrm{A} 2$} & \multicolumn{2}{|c|}{ A3 } & \\
\hline & & Prod & Tech & Prod & Tech & \\
\hline EX1 & 9 & 9 & 3 & 9 & 9 & 19683 \\
\hline \multirow[t]{2}{*}{ EX2 } & 9 & 9 & 9 & 9 & 9 & 59049 \\
\hline & $\mathrm{Al}$ & $\mathrm{A} 2$ & - & A14 & A 15 & \\
\hline EX3 & 30 & 30 & - & 30 & 30 & $1.4310^{22}$ \\
\hline
\end{tabular}

For the first class (EX1 and EX2), we have considered a simplified industrial enterprise process named Production Authorization Process (PAP) extracted from the quality manual of our industrial partner. The goal of this process is to authorize the production of a new industrial product. This process shown in figure 4 is decomposed into three activities $\mathrm{A}_{i}$ and needs actors belonging to the technical and production teams. First, a set of industrial tests is defined during A1. These tests are realized and analysed during activity A2. Then, according to the test results, either a corrective actions plan or a production proposal is generated. This last one is evaluated during activity A3 and production is authorized or not. For this process, we consider a behaviour sequence named $\sigma=\{\mathrm{A} 1, \mathrm{~A} 2, \mathrm{~A} 1, \mathrm{~A} 2, \mathrm{~A} 1, \mathrm{~A} 2, \mathrm{~A} 3\}$, where several iterations are needed before the final decision.

For this process and this behaviour $\sigma$, we have considered many human skill profiles and process constraints generating an important but computable quantity of possible allocation configurations (table 1) after the filtering phase.

For the second class of example (EX3), we have considered a virtual enterprise process composed of 15 sequential activities having themselves 30 possible allocation configurations associated with landing and randomly distributed performance. This example leads to a great amount of global resource allocation and is impossible to be considered exhaustively. It represents for use the more complex process one can imagine to analyse in an enterprise, with an acceptable granularity of description. 


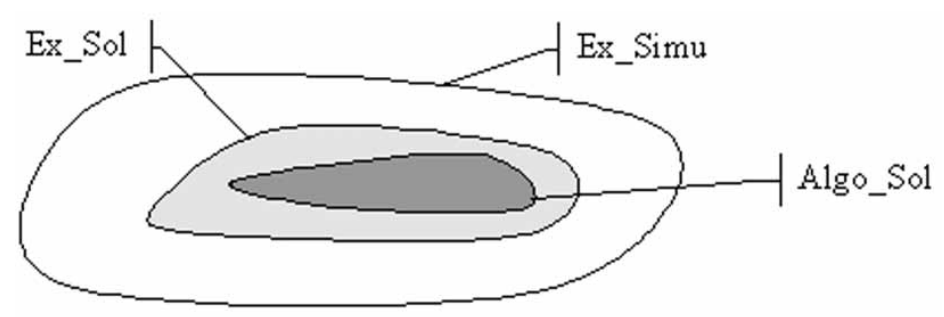

Figure 5. Comparison of the solution sets.

\subsection{Evaluation methodology}

6.2.1 Principles. When an exhaustive simulation can be done, the experimentation methodology consists to compare the efficiency of the global versus the local approach, for a performance point of view. We have considered a set of POs covering the possible range between the minimal and maximal performance of the process.

The exhaustive approach realizes all the possible simulations (set Ex_Simu in figure 5). It detects all the possible allocation solutions (set Ex_Sol in figure 5) satisfying a level of performance, but it needs for the considered allocation problem 19683 (EX1) or 59049 (EX2) simulations. This exhaustive approach will be our reference since all the solutions are detected. For the non-exact approaches, we use each of the proposed algorithms. Unfortunately, in general, all the possible solutions are not detected and only a subset (set Algo_Sol in figure 5) is found. However, this lack of detected solutions is balanced with an important decrease of the needed global simulations.

For limited complexity examples, the exhaustive simulation can be used to estimate the efficiency of the non-exact methods. When the exhaustive exploration of the solution set cannot be achieved (EX3), the comparison of the non-exact approaches is the only one that is possible. We now define two indicators that allow us to characterize algorithms efficiency when exhaustive simulation can be done.

6.2.2 Allocation coverage coefficient. The allocation coverage coefficient AC is defined by the ratio of equation (4):

$$
\mathrm{AC}=\frac{\text { Number of detected solutions }}{\text { Total number of solutions }} * 100
$$

It represents the percentage of detected solutions obtained by using a given algorithm. It corresponds to $100 \%$ for an exhaustive approach. For a set of POs, the minimum and mean allocation coverage will be certainly two good indicators of the algorithm effectiveness.

6.2.3 Efficiency coefficient. The previous coefficient cannot take into account the number of simulations needed to reach an allocation coverage. This can be done by introducing an efficiency coefficient EC (equation 5).

$$
\mathrm{EC}=\frac{\text { Allocation coverage mean }}{\text { Number of simulations mean }}
$$


The more this coefficient is close to 100 , the more efficient is the algorithm. The best but utopian algorithm would find all the allocation solutions with only one simulation. Moreover, note that for a given allocation coverage mean, this coefficient decreases very quickly when the number of simulation increases.

\subsection{Quick description of the tested algorithms}

6.3.1 Hybrid Taboo-Descent Algorithm. We used an Hybrid Taboo-Descent Algorithm. It uses a non-random initialization such as a taboo algorithm Hao et al. (1999) but without the associated list taboo. This algorithm does not tolerate the degradation of the objective function. For each iteration, like an algorithm of Descent (Hao et al. 1999), it takes the best possible neighbour to find a solution. However, this kind of approach is easily blocked in a local optimum.

6.3.2 Simulated Annealing algorithm. Simulated Annealing is a meta-heuristic algorithm (Kirkpatrick et al. 1982). This algorithm is usually used to approximate the solution of very large combinatorial problems. In theory, it avoids the classical trap into objective function local minima. It was inspired by the 'annealing' experimental technique used by metallurgists to obtain a well-ordered solid corresponding to the minimal state of energy (Metropolis et al. 1953).

6.3.3 Pisinger Algorithm. The assignment problem studied in this paper can be formulated as multiple-choice Knapsack Problem for a mono-PO satisfaction, or like a multi-multiple-choice Knapsack for a multi-PO satisfaction. For resolving this NP-hard problem, we use the minimal algorithm proposed by Pisinger (1995b) to address the multiple-choice Knapsack Problem.

\section{Allocation with mono-performance evaluation}

In this part, we present for each considered performance points of view on the following points. First, we summarize the performance estimation rules used and present a typical graph of performance evolution for PAP behaviour. We then show and comment an example of the evolution of the allocation coverage coefficient versus the PO. Finally, before concluding each paragraph, we present and explain the tables summarizing, for all examples, the main results.

All simulations were realized by computer with a Pentium IV/2 GHz processor and 1 Goctet RAM memory. Algorithms were coded in $\mathrm{C}$ language. Table 2 shows the obtained results on EX1 and EX2 for the exhaustive approach.

\subsection{Temporal point of view}

7.1.1 Performance estimation rules. The performance mechanisms used to implement the temporal point of view in the performance estimation approach, and based on the notation defined in equation (2), are summarized in table 3.

We use the nominal duration $T_{\mathrm{Nom}}$ of an activity for reference. The upstream performance UP corresponds in case of the synchronization of activities, to the date of availability of the latest (law Max) activity inputs $\left(I_{i}\right)$. For a temporal point of 
Table 2. Computation time for EX1 and EX2 exhaustive analysis.

\begin{tabular}{lcccr}
\hline & Nb simulation & Time $(\mu \mathrm{s})$ & AC $(\%)$ & \multicolumn{1}{c}{ EC } \\
\hline EX1 & 19683 & 4168 & 100 & $5 \times 10^{-3}$ \\
EX2 & 59049 & 12307 & 100 & $1.7 \times 10^{-3}$ \\
\hline
\end{tabular}

Table 3. Activity main performance items for the temoporal point of view.

\begin{tabular}{lc}
\hline$P_{i k \mathrm{~T}}$ & Activity $T_{\mathrm{Nom}}=\mathrm{Cte}$ \\
UP & $\max \left(I_{1}, \ldots, I_{n}\right)$ \\
FP & 0 \\
OP & $\mathrm{AP}+\mathrm{UP}$ \\
\hline
\end{tabular}

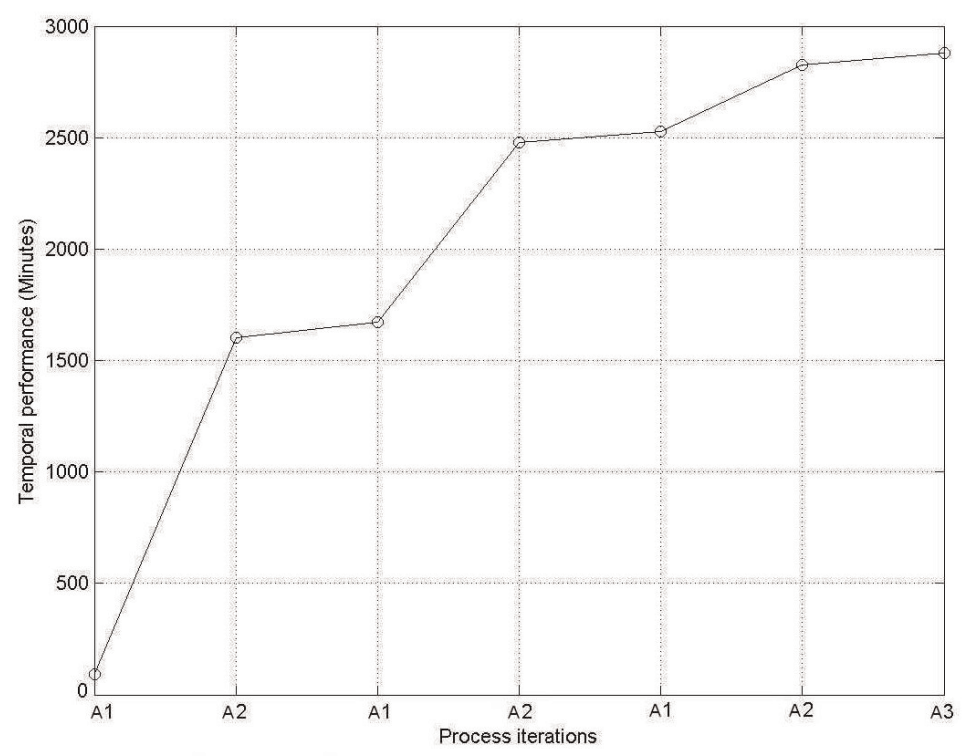

Figure 6. Typical temporal evolution curve for the process PAP.

view, the feedback behaviour is naturally taken into account and the merging law is obviously the addition.

Figure 6 proposes a typical profile of temporal performance for the enterprise process PAP and for the chosen $\sigma$, for workers having acceptable skills. The horizontal axis allows one to follow the process evolution. Each graduation corresponds to activity execution for $\sigma$ behaviour. The vertical axis represents the temporal performance in minutes. The difference between two points in the curve shows the temporal gradient corresponding to activity duration. The final point corresponds to the PAP process duration. 


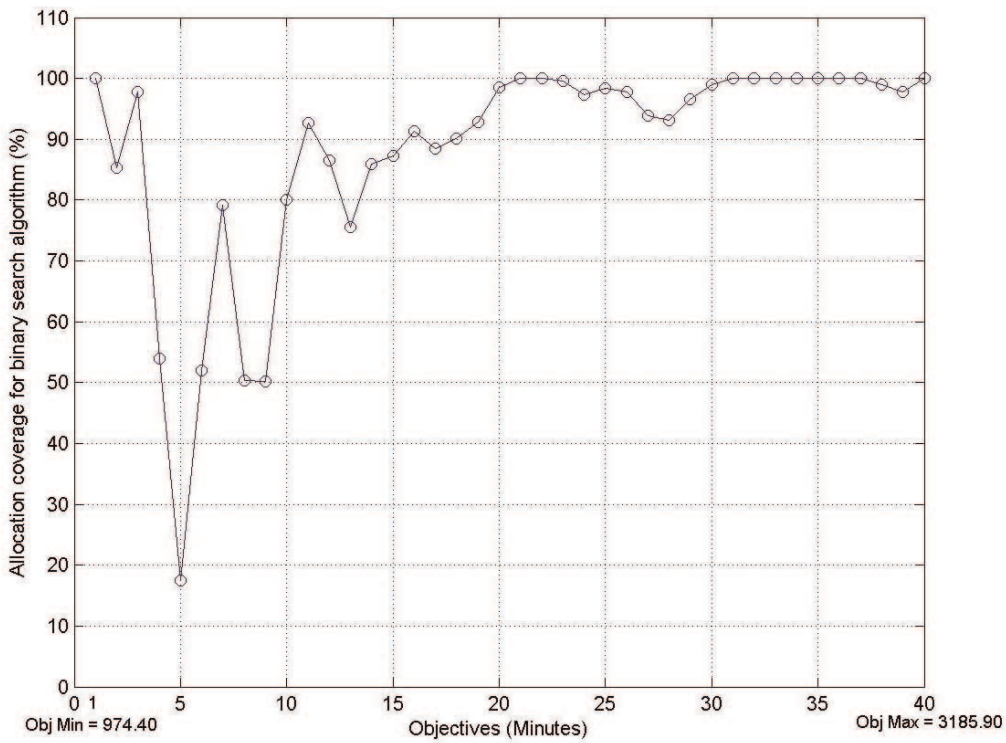

Figure 7. EX2: allocation coverage for the BSA_BK algorithm from a temporal point of view.

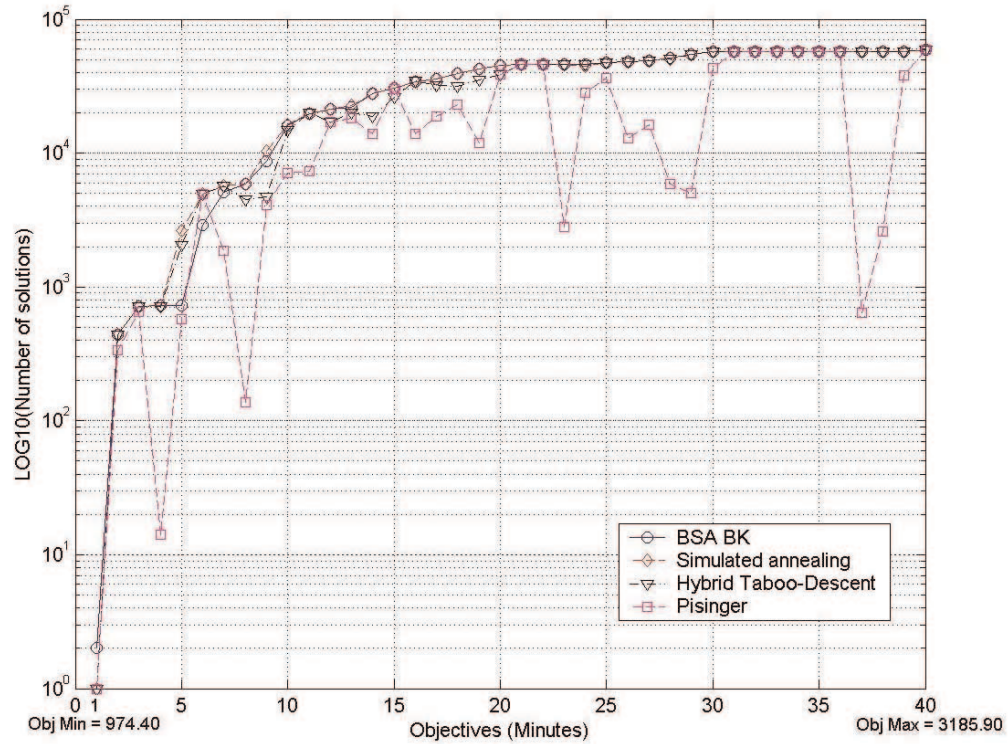

Figure 8. EX2: comparison of the found solutions from a temporal point of view.

7.1.2 Typical results curves. To evaluate the efficiency of the different algorithms, they have been tested on the different benchmarks for $40 \mathrm{PO}(\mathrm{PO} \leq \mathrm{Cte})$ regularly spaced into the accessible range of performance. Then, for these test conditions, figure 7 shows the evolution of the allocation coverage coefficient for the BSA on EX2 benchmark. Figure 8 permits one to compare the behaviour the different algorithms on EX2. 
We can see in figure 7 that for medium and high POs, the allocation coverage is very good $(>80 \%)$. We can observe an important reduction of AC for low PO. This behaviour seems normal because the smaller the PO, the more difficult is the task to find the allocation solutions. Figure 8 confirms this fact since the numbers of found solutions decrease for all the algorithm classes when the PO also decreases. This figure also shows that the results of BSA, Simulated Annealing and the Hybrid Taboo-Descent Algorithms are equivalent, whereas the Pisinger approach is clearly the worst.

7.1.3 Results tables. Tables 4-6 summarize the main results obtained on EX1 and EX2 for the different algorithms.

7.1.4 Discussion. Concerning the results obtained from the basic BSA (table 4) for the limited complexity examples (EX1, EX2), fewer than ten simulations are needed to obtain a set of human allocation possibilities in few microseconds. Globally, an

Table 4. Temporal point of view: results for EX1 and EX2 with Binary Search Algorithms.

\begin{tabular}{|c|c|c|c|c|c|c|c|c|c|c|}
\hline & \multicolumn{5}{|c|}{ BSA } & \multicolumn{5}{|c|}{ BSA_BK } \\
\hline & \multirow{2}{*}{$\frac{\begin{array}{c}\mathrm{Nb} \\
\text { simulation }\end{array}}{\text { Mean }}$} & \multicolumn{2}{|c|}{$\mathrm{AC}(\%)$} & \multirow{2}{*}{$\frac{\mathrm{EC}}{\text { Mean }}$} & \multirow{2}{*}{$\begin{array}{l}\text { Max } \\
\text { time } \\
(\mu \mathrm{s})\end{array}$} & \multirow{2}{*}{$\frac{\begin{array}{c}\mathrm{Nb} \\
\text { simulation }\end{array}}{\text { Mean }}$} & \multicolumn{2}{|c|}{$\mathrm{AC}(\%)$} & \multirow{2}{*}{$\frac{\mathrm{EC}}{\mathrm{Mead}}$} & \multirow{2}{*}{$\begin{array}{c}\text { Max } \\
\text { time } \\
(\mu \mathrm{s})\end{array}$} \\
\hline & & Minimum & Mean & & & & Minimum & Mean & & \\
\hline EX1 & 8.45 & 15.25 & 87.87 & 10.40 & 13 & 8.98 & 15.25 & 90.06 & 10.03 & 17 \\
\hline EX2 & 9.65 & 1.35 & 86.09 & 8.92 & 13 & 10.40 & 17.54 & 88.19 & 8.48 & 18 \\
\hline
\end{tabular}

Table 5. Temporal point of view: results for EX1 and EX2 with Hybrid Taboo-Descent and Simulated Annealing Algorithms.

\begin{tabular}{|c|c|c|c|c|c|c|c|c|c|c|}
\hline & \multicolumn{5}{|c|}{ Hybrid Taboo-Descent } & \multicolumn{5}{|c|}{ Simulated annealing } \\
\hline & $\begin{array}{c}\mathrm{Nb} \\
\text { simulation }\end{array}$ & $\mathrm{AC}(\%$ & & $\mathrm{EC}$ & $\operatorname{Max}$ & $\begin{array}{c}\mathrm{Nb} \\
\text { simulation }\end{array}$ & $\mathrm{AC}(\%$ & & EC & $\operatorname{Max}$ \\
\hline & Mean & Minimum & Mean & Mean & $(\mu \mathrm{s})$ & Mean & Minimum & Mean & Mean & $(\mu \mathrm{s})$ \\
\hline EX1 & 68.67 & 5.55 & 82.73 & 1.20 & 509.00 & 39.43 & 48.54 & 90.42 & 2.29 & 39438 \\
\hline EX2 & 70.42 & 27.10 & 84.82 & 1.20 & 272.00 & 54.05 & 50 & 89.49 & 1.65 & 40338 \\
\hline
\end{tabular}

Table 6. Temporal point of view: results for EX1 and EX2 for the Pisinger Algorithm.

\begin{tabular}{|c|c|c|c|c|c|}
\hline & \multirow{2}{*}{$\frac{\mathrm{Nb} \text { simulation }}{\text { Mean }}$} & \multicolumn{2}{|c|}{$\mathrm{AC}(\%)$} & \multirow{2}{*}{$\frac{\mathrm{EC}}{\text { Mean }}$} & \multirow{2}{*}{$\begin{array}{c}\text { Maxi } \\
\text { time }(\mu \mathrm{s}\end{array}$} \\
\hline & & Minimum & Mean & & \\
\hline EX1 & 5.55 & 0.98 & 65.95 & 11.88 & 735 \\
\hline EX2 & 5.65 & 1.03 & 55.05 & 9.74 & 17574 \\
\hline
\end{tabular}


allocation coverage mean $>86 \%$ is reached. These results lead to a good efficiency coefficient of nearly ten. The use of the backtrack permits one to gain about $3 \%$ of allocation coverage mean with more simulations. The benefit of the backtrack is particularly significant for the minimal allocation coverage for EX2, which increases by more than $15 \%$. Evidently, the increase of simulations leads to a little decrease of the efficiency coefficient, which remains quite good and near ten.

For the same examples, the Simulated Annealing algorithms lead to the same allocation coverage $(89 \%)$ than the Binary Search approach with backtrack. However, this good result needs an important amount of simulations (more than 39) and then leads to a worst efficiency coefficient of between 1.5 and 3.0.

By comparison, the results of the Hybrid Taboo-Descent Algorithm (table 5) are lower by comparison with BSA and Simulated Annealing algorithms. A quite good allocation coverage of approximately $82 \%$ is obtained, but it needs seven or eight times more simulations.

The algorithm proposed by Pisinger is the worst with regards to the allocation coverage, which remains near $60 \%$. However, its efficiency coefficient is the best because it needs few simulations.

Therefore, for the temporal point of view, which corresponds to a less or equal objective class, we can conclude that, on the one hand, the Binary Search, Hybrid Taboo-Descent and Simulated Annealing methods find approximately the same quantity of solutions. On the other hand, the Pisinger Algorithm is clearly the worst. However, its efficiency is better than the other ones because it needs fewer simulations by comparison with the other algorithms.

\subsection{Financial point of view}

7.2.1 Performance estimation rules. The performance mechanisms used to implement the financial point of view in the performance estimation approach are summarized in table 7.

For the financial point of view, from the knowledge of workers and material cost, we take into account the previous results concerning the resources (human and material) using time to determine the cost of each activity (AP) and finally for the global process. All the money yet used must be added (law $\Sigma$ for UP and AP). Feedback is directly considered with UP and AP performances. We do not show here the typical financial performance evolution curve for the studied process since its aspect is the same as the temporal view point. Since the financial cost of a process can only increase, the corresponding evolution is an increasing monotonic curve.

Table 7. Activity main performance items for the financial point of view.

\begin{tabular}{lc}
\hline & Deduced from \\
AP & temporal performance \\
UP & $\Sigma I_{i}$ \\
FP & 0 \\
OP & $\mathrm{AP}+\mathrm{UP}$ \\
\hline
\end{tabular}




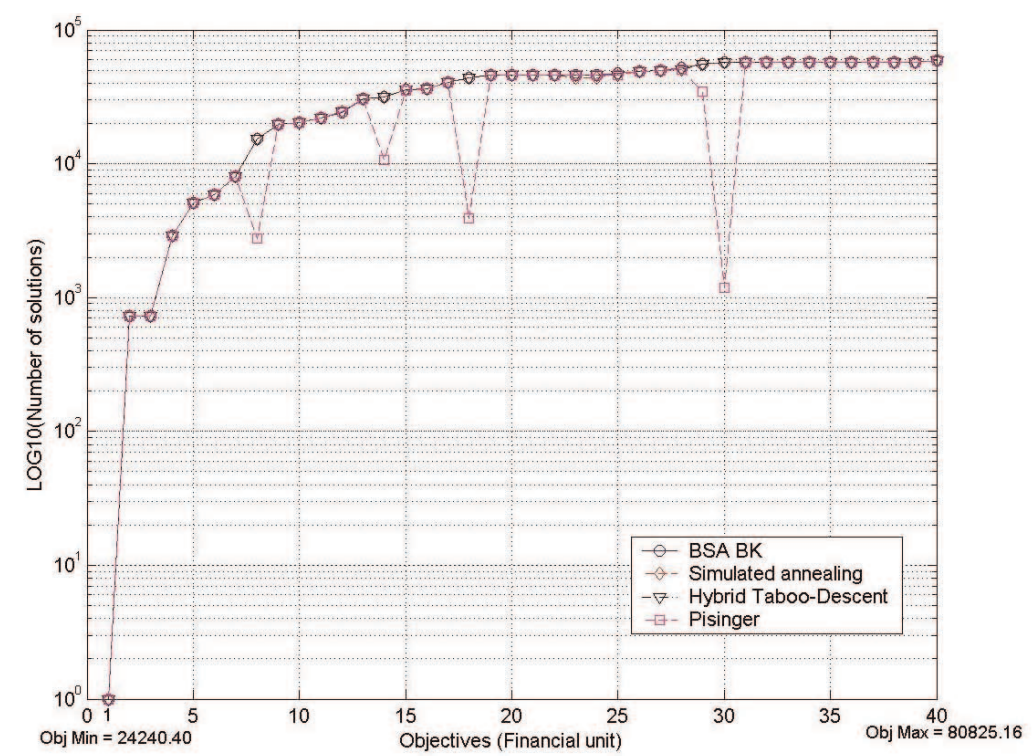

Figure 9. EX2: comparison of the found solutions from a financial point of view.

7.2.2 Typical results curves. Due to the important similarity between the financial and temporal points of view (monotonic performance evolution curve and $\mathrm{PO} \leq \mathrm{Cte}$ ), we show the graph (figure 9) showing for EX2 a comparison of the tested algorithms.

This graph has clearly the same aspect than figure 8. A decrease of the number of found solutions is observed for low POs. Similar to the temporal point of view, the results of Hybrid Taboo-Descent, Simulated Annealing and BSA are qualitatively equivalent. However, we note that Pisinger Algorithm detects fewer solutions, but it remains excellent.

7.2.3 Results tables. Tables $8-10$ shows the main results observed on EX1 and EX2 for the tested algorithms.

7.2.4 Discussion. Table 8 shows that the Binary Search-based approach generates excellent results. An allocation coverage mean $>99 \%$ is obtained with about ten simulations and a few microseconds. We can also observed that contrary to the temporal point of view, the backtrack does not improve allocation coverage. The cost to be paid for the backtrack is a reduction in the efficiency coefficient because more simulations are realized without detection of new solutions.

Simulated Annealing permits us to reach good allocation coverage $>99 \%$ and equivalent to the Binary Search-based algorithm, but it presents the higher maximum time compared with the other algorithms.

The Hybrid Taboo-Descent Algorithm presents the same excellent allocation coverage. However, due to the amount of needed simulations, its efficiency coefficient is very bad (table 9). The good allocation coverage of the Pisinger Algorithm (table 10) is lower with $<95 \%$. However, it presents the highest efficiency coefficient due to the low number of simulations. 
Table 8. Financial point of view: results for EX1 and EX2 with Binary Search Algorithms.

\begin{tabular}{|c|c|c|c|c|c|c|c|c|c|c|}
\hline & \multicolumn{5}{|c|}{ BSA } & \multicolumn{5}{|c|}{ BSA_BK } \\
\hline & $\begin{array}{c}\mathrm{Nb} \\
\text { simulation }\end{array}$ & \multicolumn{2}{|c|}{$\mathrm{AC}(\%)$} & \multirow{2}{*}{$\frac{\mathrm{EC}}{\text { Mean }}$} & \multirow{2}{*}{$\begin{array}{l}\text { Max } \\
\text { time } \\
(\mu \mathrm{s})\end{array}$} & \multirow{2}{*}{$\frac{\begin{array}{c}\mathrm{Nb} \\
\text { simulation }\end{array}}{\text { Mean }}$} & \multicolumn{2}{|c|}{$\mathrm{AC}(\%)$} & \multirow{2}{*}{$\frac{\mathrm{EC}}{\text { Mean }}$} & \multirow{2}{*}{$\begin{array}{l}\text { Max } \\
\text { time } \\
(\mu \mathrm{s})\end{array}$} \\
\hline & Mean & Minimim & Mean & & & & Minimum & Mean & & \\
\hline EX1 & 8.38 & 96.09 & 99.82 & 11.92 & 13 & 8.58 & 96.09 & 99.82 & 11.64 & 18 \\
\hline EX2 & 9.72 & 97.06 & 99.65 & 10.24 & 12 & 10 & 97.06 & 99.65 & 9.96 & 17 \\
\hline
\end{tabular}

Table 9. Financial point of view: results for EX1 and EX2 with Hybrid Taboo-Descent and Simulated Annealing Algorithms.

\begin{tabular}{|c|c|c|c|c|c|c|c|c|c|c|}
\hline & \multicolumn{5}{|c|}{ Hybrid Taboo-Descent } & \multicolumn{5}{|c|}{ Simulated Annealing } \\
\hline & $\begin{array}{c}\mathrm{Nb} \\
\text { simulation }\end{array}$ & $\mathrm{AC}(\%$ & & $\mathrm{EC}$ & $\operatorname{Max}$ & $\begin{array}{c}\mathrm{Nb} \\
\text { simulation }\end{array}$ & $\mathrm{AC}(\%$ & & EC & Max \\
\hline & Mean & Minimum & Mean & Mean & $(\mu \mathrm{s})$ & Mean & Minimum & Mean & Mean & $(\mu \mathrm{s})$ \\
\hline EX1 & 78.80 & 11.11 & 97.35 & 1.24 & 270 & 31.93 & 93.75 & 99.66 & 3.12 & 36290 \\
\hline EX2 & 78.77 & 95.07 & 99.55 & 1.26 & 387 & 38.17 & 95.23 & 99.45 & 2.60 & 38739 \\
\hline
\end{tabular}

Table 10. Financial point of view: results for EX1 and EX2 for Pisinger Algorithms.

\begin{tabular}{|c|c|c|c|c|c|}
\hline & \multirow{2}{*}{$\frac{\mathrm{Nb} \text { simulation }}{\text { Mean }}$} & \multicolumn{2}{|c|}{$\mathrm{AC}(\%)$} & \multirow{2}{*}{$\frac{\mathrm{EC}}{\text { Mean }}$} & \multirow{2}{*}{$\begin{array}{l}\text { Max } \\
\text { time } \\
(\mu \mathrm{s})\end{array}$} \\
\hline & & Minimum & Mean & & \\
\hline EX1 & 5.80 & 11.11 & 95.32 & 16.43 & 912 \\
\hline EX2 & 5.80 & 2.08 & 90.26 & 15.56 & 35895 \\
\hline
\end{tabular}

Therefore, from a financial point of view that satisfies the less or equal objective, the performance of the Binary Search approach remains globally excellent and better than the Simulated Annealing, Hybrid Taboo-Descent and Pisinger approaches.

\subsection{Quality point of view}

7.3.1 Performance estimation rules. Table 11 shows the main principles to be implemented in the performance estimation process of the quality point of view. These mechanisms are directly inspired from the working evaluation quality used in our industrial partner.

From this quality viewpoint, each activity performance AP is generated inside an interval $[-100,+100]$. Upstream performance is obtained by summing all the task qualities encountered from the beginning of the process to the considered activity. Initially, output performance is computed by adding the upstream and self-activity performances. This assumption of an additive model for a quality point of view is 
Table 11. Activity main performance items for a quality point of view.

\begin{tabular}{lc}
\hline AP & $\in[-100,+100]$ \\
UP & $\Sigma I_{\mathrm{i}}$ \\
FP & User definec \\
OP & $\mathrm{AP}+\mathrm{UP}+\mathrm{FP}$ \\
\hline
\end{tabular}

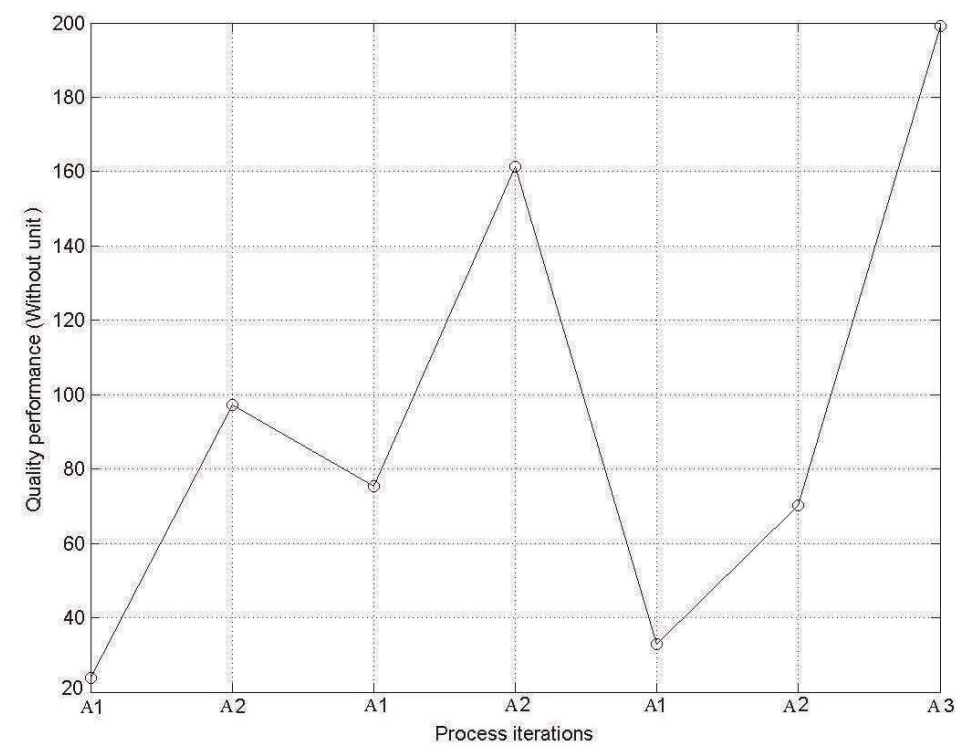

Figure 10. Typical quality evolution curve for process PAP.

also retained by Norman et al. (2002). At this point, since positive or negative quality performances can be observed, contrary to the temporal or financial point of view, the quality evolution is not necessary monotonic. Moreover, this model of quality integration does not take into account the occurrence of an iteration into the process evolution.

This behaviour induces automatically a penalization from a temporal or a financial point of view. This penalty can be artificially introduced as the quality model by using as feedback performance the FP user's defined laws. An example shows a typical profile of quality performance for the studied enterprise process PAP and its behaviour $\sigma$ for workers with acceptable skills. In figure 10, the horizontal axis allows one to follow the process evolution and activity execution. The vertical axis represents quality performance without units. The difference between two points on the curve represents the quality impact of an activity. In the chosen model, we have considered that an iteration in the process behaviour expresses the fact that the work has been done badly even if the worker has been correctly chosen. This lack of quality is then artificially taken into account by using a feedback law introducing a penalty proportional with the number of iterations. On figure 10, this lack of quality, non-correlated with human skills, is observed when the curve decreases. 


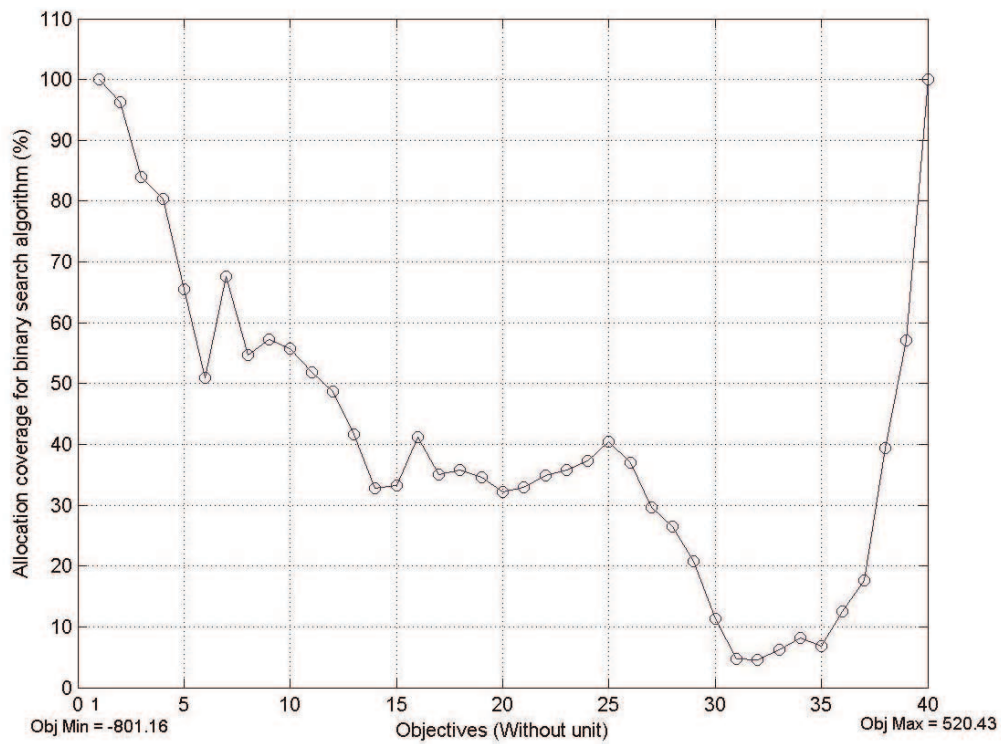

Figure 11. EX2: allocation coverage for BSA algorithm from a quality point of view.

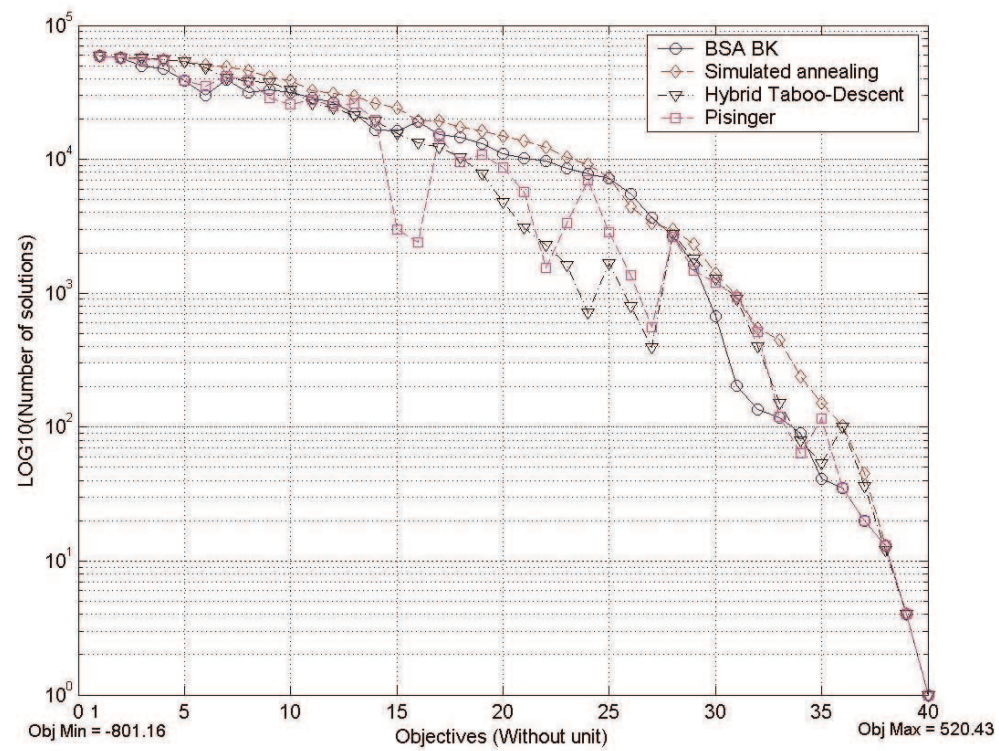

Figure 12. EX2: comparison of the found solutions from a quality point of view.

7.3.2 Typical results curves. Figures 11 and 12 present the result of the different tested algorithms on the benchmark EX2 for a quality PO. Contrary to the previous objectives that intend to minimize time and cost, we search to maximize quality. Therefore, we are looking for the human allocations that satisfy the global process $\mathrm{P}_{\mathrm{Q}} \geq \mathrm{PO}_{\mathrm{Q}}$. 
Figure 11 shows the allocation coverage obtained for different PO regularly distributed into the quality range. It is clear that the results are worse than for the temporal and financial viewpoint. More than half of the solutions are $<40 \%$ of allocation coverage. However, this observation can be modulated with the analysis of figure 12. It shows the number of allocation solutions found for the different classes of algorithm. First, it is logical to observe a decrease of the solutions when the quality PO increases, since it is increasingly more difficult to satisfy it. Second, contrary to the previous considered performance, all the algorithms seem to generate globally the same amount of solutions, and then an equivalent allocation coverage.

7.3.3 Results tables. Tables $12-14$ summarize the main results obtained by the different classes of algorithms on the limited complexity benchmarks EX1 and EX2.

Table 12. Quality point of view: results for EX1 and EX2 with Binary Search Algorithms.

\begin{tabular}{|c|c|c|c|c|c|c|c|c|c|c|}
\hline & \multicolumn{5}{|c|}{ BSA } & \multicolumn{5}{|c|}{ BSA_BK } \\
\hline & \multirow{2}{*}{$\frac{\begin{array}{c}\mathrm{Nb} \\
\text { simulation }\end{array}}{\text { Mean }}$} & \multicolumn{2}{|c|}{$\mathrm{AC}(\%)$} & \multirow{2}{*}{$\frac{\mathrm{EC}}{\text { Mean }}$} & \multirow{2}{*}{$\begin{array}{l}\text { Max } \\
\text { time } \\
(\mu \mathrm{s})\end{array}$} & \multirow{2}{*}{$\frac{\begin{array}{c}\mathrm{Nb} \\
\text { simulation }\end{array}}{\text { Mean }}$} & \multicolumn{2}{|c|}{$\mathrm{AC}(\%)$} & \multirow{2}{*}{$\frac{\mathrm{EC}}{\text { Mean }}$} & \multirow{2}{*}{$\begin{array}{c}\text { Max } \\
\text { time } \\
(\mu \mathrm{s})\end{array}$} \\
\hline & & Minimum & Mean & & & & Minimum & Mean & & \\
\hline EX1 & 18.75 & 8.45 & 45.96 & 2.45 & 23 & 19.55 & 8.45 & 45.96 & 2.35 & 24 \\
\hline EX2 & 19.32 & 4.58 & 41.58 & 2.15 & 25 & 20.02 & 4.58 & 41.58 & 2.07 & 24 \\
\hline
\end{tabular}

Table 13. Quality point of view: results for EX1 and EX2 with Hybrid Taboo-Descent and Simulated Annealing Algorithms.

\begin{tabular}{|c|c|c|c|c|c|c|c|c|c|c|}
\hline & \multicolumn{5}{|c|}{ Hybrid Taboo-Descent } & \multicolumn{5}{|c|}{ Simulated Annealing } \\
\hline & $\begin{array}{c}\mathrm{Nb} \\
\text { simulation }\end{array}$ & $\mathrm{AC}(\%$ & & $\mathrm{EC}$ & $\operatorname{Max}$ & $\begin{array}{c}\mathrm{Nb} \\
\text { simulation }\end{array}$ & $\mathrm{AC}(\%$ & & EC & $\operatorname{Max}$ \\
\hline & Mean & Minimum & Mean & Mean & $(\mu \mathrm{s})$ & Mean & Minimum & Mean & Mean & $(\mu \mathrm{s})$ \\
\hline EX1 & 23.85 & 4.61 & 33.98 & 1.42 & 250 & 98.08 & 28.42 & 54.04 & 0.55 & 39632 \\
\hline EX2 & 34.18 & 3.15 & 39.34 & 1.15 & 388 & 135.05 & 18.54 & 52.32 & 0.38 & 39891 \\
\hline
\end{tabular}

Table 14. Quality point of view: results for EX1 and EX2 for the Pisinger Algorithm.

\begin{tabular}{|c|c|c|c|c|c|}
\hline & \multirow{2}{*}{$\frac{\mathrm{Nb} \text { simulation }}{\text { Mean }}$} & \multicolumn{2}{|c|}{$\mathrm{AC}(\%)$} & \multirow{2}{*}{$\frac{\mathrm{EC}}{\text { Mean }}$} & \multirow{2}{*}{$\begin{array}{l}\text { Max time } \\
\quad(\mu \mathrm{s})\end{array}$} \\
\hline & & Minimum & Mean & & \\
\hline EX1 & 5.47 & 1.84 & 37.68 & 6.88 & 11282 \\
\hline EX2 & 5.37 & 4.50 & 37.80 & 7.03 & 50361 \\
\hline
\end{tabular}


7.3.4 Discussion. Concerning allocation coverage, the results of tables 12-14 confirm the behaviour of the algorithms shown in figure 12. All allocation coverage means are between 33 and $54 \%$. The best ones are obtained by the Simulated Annealing algorithm with $52 \%$ for EX 2 and $54 \%$ with EX1 of coverage.

The use of the backtrack for the BSA is totally ineffective since the increase of simulation generates no gain in allocation coverage. However, the allocation coverage, which is around $42 \%$ (table 12), is higher than for the Hybrid TabooDescent and Pisinger Algorithms. Despite its limited allocation coverage, the Pisinger approach remains the more efficient, with fewer than six simulations to obtain a solution. Moreover, the good coverage results of the Simulated Annealing algorithm lead to the worst efficiency coefficient due to the large amount of simulations needed.

After having considered some benchmarks with limited complexity, we will now check the algorithms on the virtual example EX3.

\subsection{Large dimensions benchmarks}

Since for the benchmark EX3 the activities performance values have been generated randomly, we just study in the following the behaviour of the algorithms faced to the two main PO classes, less or equal, and greater or equal.

In figure 13, the comparison of the solutions for the less or equal objective shows that the BSA, Simulated Annealing and Hybrid Taboo-Descent Algorithms are equivalent for upper half part of the figure. The Pisinger approach is clearly the worst. Unfortunately, the performance of the BSA falls in the lower part of the figure when the solutions are more difficult to find.

In figure 14, for the greater or equal PO, the dual behaviour is observed. Our algorithm has more difficulties in dealing with this class of objective. However, the performance of the Pisinger approach remains the worst. Therefore, even if the

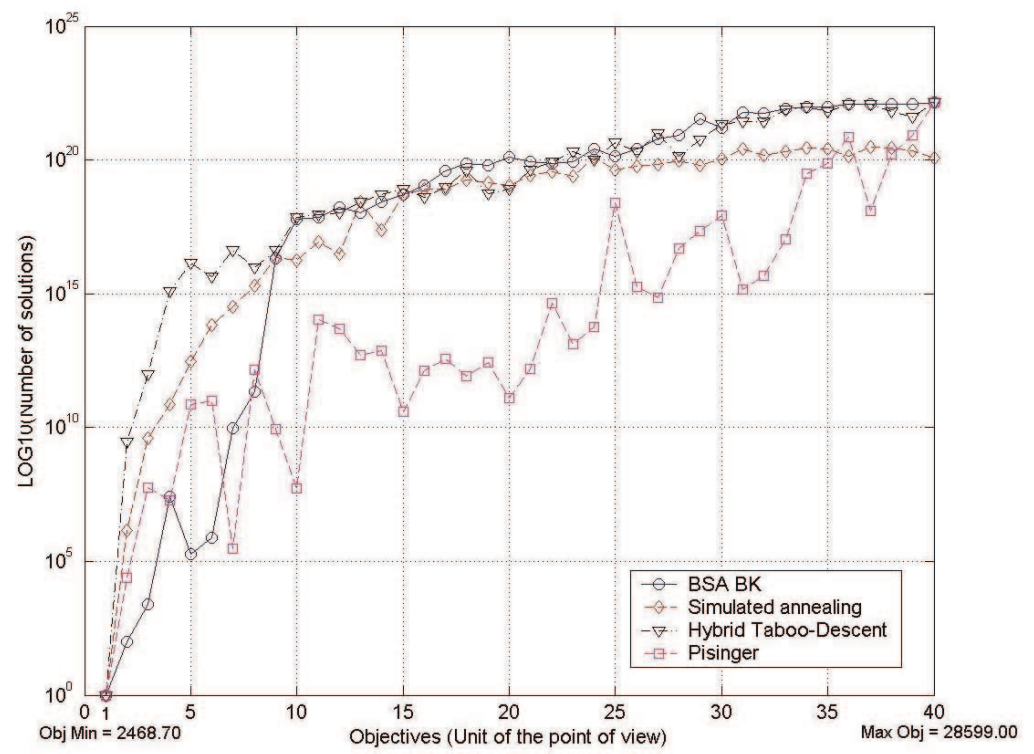

Figure 13. Comparison of the algorithms for a less or equal performance objective. 


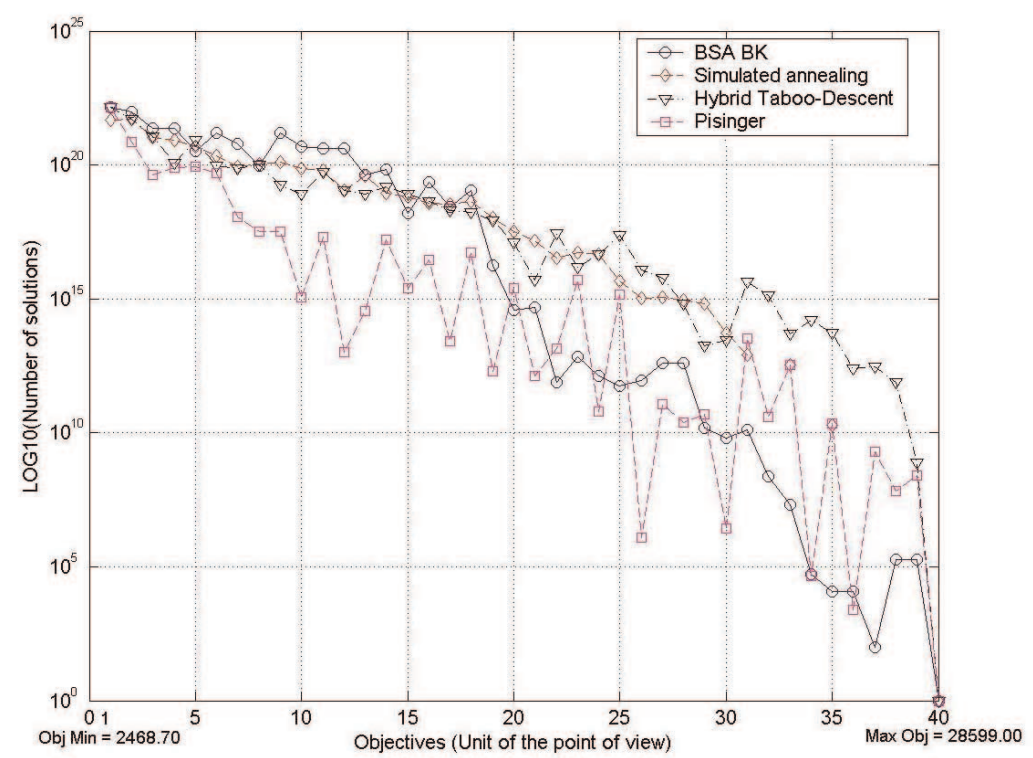

Figure 14. Comparison of the algorithms for a greater or equal performance objective.

Table 15. Performance objective less than or equal—results for EX3.

\begin{tabular}{lccccc}
\hline & BSA & BSA_BK & $\begin{array}{c}\text { Simulated } \\
\text { Annealing }\end{array}$ & $\begin{array}{c}\text { Hybrid } \\
\text { Taboo-Descent }\end{array}$ & $\begin{array}{c}\text { Pisinger } \\
\text { Algorithm }\end{array}$ \\
\hline NS $_{\text {mean }}$ & 59.72 & 64.47 & 195.02 & 21.05 & 4.32 \\
Maximum time $(\mu \mathrm{s})$ & 110 & 111 & 181080 & 3011490 & 279762 \\
\hline
\end{tabular}

Table 16. Performance objective greater than-results for EX3.

\begin{tabular}{lccccc}
\hline & BSA & BSA_BK & $\begin{array}{c}\text { Simulated } \\
\text { Annealing }\end{array}$ & $\begin{array}{c}\text { Hybrid } \\
\text { Taboo-Descent }\end{array}$ & $\begin{array}{c}\text { Pisinger } \\
\text { Algorithm }\end{array}$ \\
\hline $\mathrm{NS}_{\text {mean }}$ & 51.82 & 61.42 & 195.02 & 16.40 & 3.82 \\
Maximum time $(\mu \mathrm{s})$ & 96 & 96 & 178728 & 3070340 & 1079360 \\
\hline
\end{tabular}

allocation coverage is not computable for EX3, we can conclude that the Hybrid Taboo-Descent and Simulated Annealing algorithms are better than the Binary Search-based and Pisinger approaches.

Moreover, due to the dimensions of some solution sets, it is not realistic to compute the average number of obtained solutions. Therefore, we propose for each kind of algorithm in tables 15 and 16 the average number of simulations, $\mathrm{NS}_{\text {mean }}$, and the maximal time of computing observed.

For the BSA algorithm, the number of needed simulations remains limited and lower than the other one, except for the Pisinger approach. For Simulated Annealing, it is still constant with regards to the number of simulations observed for the limited complexity benchmarks. Our approach keeps a very limited 
simulation time (a few microseconds) with regards to the other algorithms $(0.2 \mathrm{~s}$ and more).

\subsection{Global conclusion for the mono-performance estimation}

First, for the limited complexity examples, the affectation results are obtained in a very short time, whatever the algorithm class used (exhaustive, non-exact). For the large example, it is clear that the exhaustive approach is not useable. Moreover, a large dispersion of simulation time is observed between the microseconds and seconds. The discrimination condition between the exhaustive and non-exact approaches will be discussed below.

Two classes of PO have been investigated, the less or equal class for the temporal and financial point of view and the greater or equal class for the quality point of view.

Concerning the limited complexity benchmarks, the proposed approach based on BSA seems globally to be the best. Its results are excellent for the less or equal class. For the greater or equal class, a decrease of the found solutions is observed for all the tested algorithms and their efficiency is globally equivalent.

Concerning the large dimension benchmark, the Binary Search-based Algorithm remains the quickest. However, the amount of detected solutions (figures 13 and 14) is generally lower than for the Simulated Annealing and Hybrid Taboo-Descent approaches, especially for the greater or equal class. This bad result can have two main origins. First, the initial performance distribution on each 'virtual' activity does not reflect exactly the distribution profile that would be observed by using the performance estimation method used for EX1 and EX2. Second, our Binary Search-based approach does not reconsider a treated activity. Therefore, its efficiency is strongly connected with the relevance of the heuristic of activity treatment. When a large number of activities are considered, a little permutation in the treatment order can have a great influence on the final amount of found allocation solutions.

Moreover, the Pisinger Algorithm, which has been developed to deal with the Knapsack Problem, leads to the worst results for the allocation coverage. We think this surprising result comes from a small difference among the goals of the algorithms. On the one hand, the Pisinger Algorithm optimizes globally the performance of the process in order to fill at best the Knapsack. We then deduce the resource effectuation set. On the other hand, the other algorithms have been developed to satisfy simultaneously two goals: to satisfy at best the PO and to maximize the amount of found solutions.

Since for an enterprise real performance is in fact multidimensional, we will now extend the previous approaches to integrate several PO such as process duration, cost and quality.

\section{Allocation with multi-performance evaluation}

\subsection{Iterative multi-objectives algorithm}

We present here a simple method allowing one to integrate simultaneously many PO constraints for human tasks allocation. These objectives come generally 


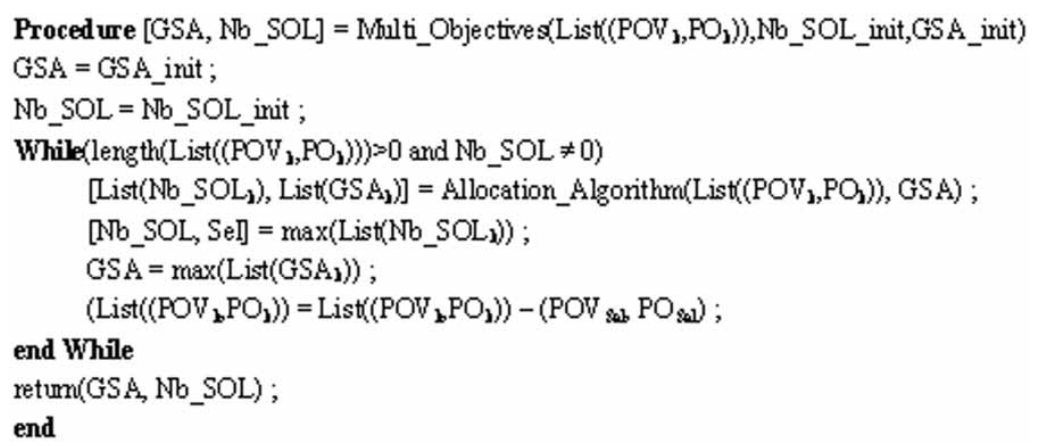

Figure 15. Pseudo-code of the iterative multi-objectives algorithm.

into conflict because, for example, efficient and capable workers reduce an activity duration but can increase its associated cost. Therefore, the allocation task must be more difficult.

To take into account several points of view $\left(\mathrm{POV}_{k}\right)$, the basic idea is to use iteratively a human selection algorithm with different $(k) \mathrm{PO}\left(\mathrm{PO}_{k}\right)$ to be satisfied (figure 15). At the end of each loop, the PO having the greater set of allocation solutions (GSA) is eliminated (selected, Sel). Then a new loop is realized by reducing the activities performances levels to the values associated to the elements of the GSA. This set is then reduced loop after loop until the satisfaction of all the PO or an empty GSA (no solution) is achieved. Finally, the elements of the obtained allocation set satisfy necessary all the Objective Performance imposed.

This multi-objectives approach is now evaluated by using the different studied algorithms.

\subsection{Evaluation of the algorithms}

8.2.1 Results. To evaluate this multi-objectives algorithm on the limited complexity benchmarks, we have taken the same approach as for the mono-objective. First, we have studied the problem of human allocation for the process PAP with temporal, financial and quality PO constraints. Moreover, we have considered a set of multi-objectives regularly distributed in the performance space and evaluated the allocation coverage by comparing the obtained solutions with the exhaustive one.

One thousand PO (temporal, financial, quality) were tested. Figure 16 presents, for EX2, the allocation coverage for 40 PO representing the global behaviour of the BSA, Simulated Annealing, Hybrid Taboo-Descent and Pisinger Algorithms. The results have been ordered following the increase of allocation coverage.

Tables 17-19 summarize the main results obtained for the tested algorithms on the limited complexity benchmarks EX1 and EX2 for 1000 objectives.

8.2.2 Discussion. Figure 16 shows three main parts. For more than $30 \%$ of Objectives, all the possible allocations are reached. For $12 \%$ of Objectives, no solution is detected. For more than $50 \%$, many solutions are found, but with an 


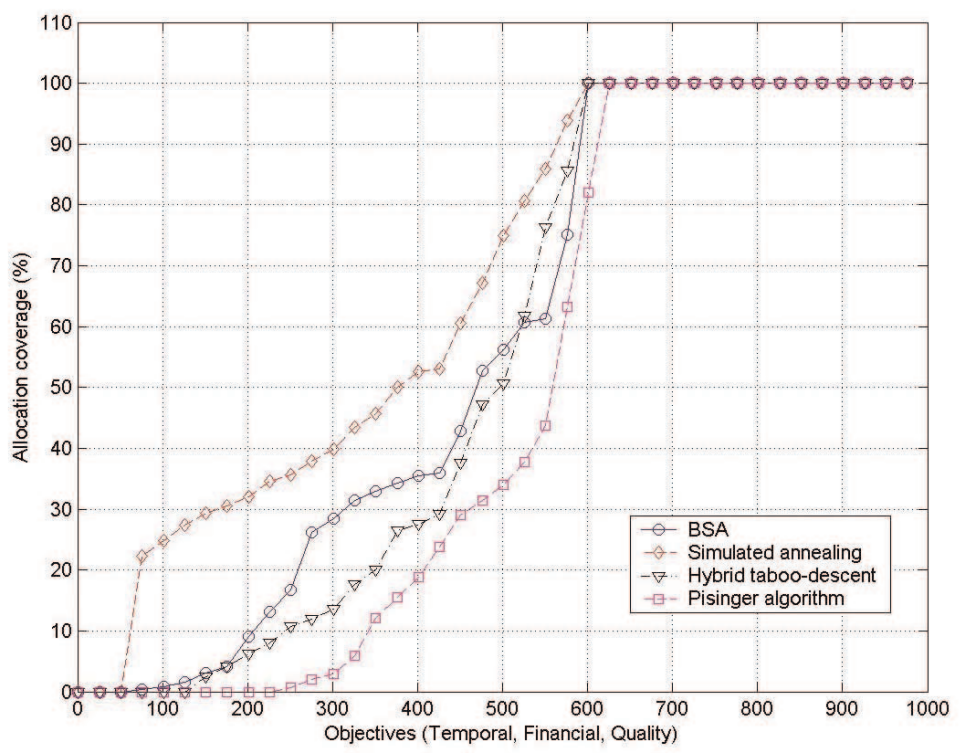

Figure 16. EX2: ordered allocation coverage for multi-performance objectives.

Table 17. Multi-point of view: results for EX1 and EX2 with Binary Search Algorithms.

\begin{tabular}{|c|c|c|c|c|c|c|c|c|c|c|}
\hline & \multicolumn{5}{|c|}{ BSA } & \multicolumn{5}{|c|}{ BSA_BK } \\
\hline & $\begin{array}{c}\mathrm{Nb} \\
\text { simulation }\end{array}$ & \multicolumn{2}{|c|}{$\mathrm{AC}(\%)$} & \multirow{2}{*}{$\frac{\mathrm{EC}}{\text { Mean }}$} & \multirow{2}{*}{$\begin{array}{c}\text { Max } \\
\text { time (s) }\end{array}$} & $\begin{array}{c}\mathrm{Nb} \\
\text { simulatin }\end{array}$ & \multicolumn{2}{|c|}{$\mathrm{AC}(\%)$} & \multirow{2}{*}{$\frac{\mathrm{EC}}{\text { Mean }}$} & \multirow{2}{*}{$\begin{array}{c}\operatorname{Max} \\
\text { time }(\mu \mathrm{s})\end{array}$} \\
\hline & Mean & Minimum & Mean & & & Mean & Minimum & Mean & & \\
\hline EX1 & 31.72 & 0 & 61.63 & 1.93 & 90 & 33.71 & 0 & 62.21 & 1.85 & 54 \\
\hline EX2 & 40.05 & 0 & 56.59 & 0.70 & 519 & 42.19 & 0 & 57.07 & 073 & 134 \\
\hline
\end{tabular}

Table 18. Multi-point of view: results for EX1 and EX2 with Hybrid Taboo-Descent and Simulated Annealing Algorithms.

\begin{tabular}{|c|c|c|c|c|c|c|c|c|c|c|}
\hline & \multicolumn{5}{|c|}{ Hybrid Taboo-Descent } & \multicolumn{5}{|c|}{ Simulated Annealing } \\
\hline & $\begin{array}{c}\mathrm{Nb} \\
\text { simulation }\end{array}$ & $\mathrm{AC}(\%$ & & EC & & $\begin{array}{c}\mathrm{Nb} \\
\text { simulation }\end{array}$ & $\mathrm{AC}(\%$ & & EC & \\
\hline & Mean & Minimum & Mean & Mean & time (s) & Mean & Minimum & Mean & Mean & time $(\mu \mathrm{s})$ \\
\hline EX1 & 137 & 0 & 50.69 & 0.37 & 892 & 111.05 & 0 & 68.55 & 0.62 & 90542 \\
\hline EX2 & 149.27 & 0 & 54.68 & 2.72 & 849 & 182.37 & 0 & 66.87 & 2.72 & 116062 \\
\hline
\end{tabular}

heterogeneous allocation coverage between 1 and $66 \%$. In each of these three areas, a detailed analysis of the multi-objectives performance value does not show a particular correlation between the allocation coverage and the PO.

The allocation coverage mean for BSA (table 17) remains acceptable with more than $50 \%$ of allocation coverage. Globally, despite the several simulations needed 
Table 19. Multi-point of view: results for EX1 and EX2 with the Pisinger Algorithm.

\begin{tabular}{|c|c|c|c|c|c|}
\hline & \multirow{2}{*}{$\frac{\mathrm{Nb} \text { simulation }}{\text { Mean }}$} & \multicolumn{2}{|c|}{$\mathrm{AC}(\%)$} & \multirow{2}{*}{$\frac{\mathrm{EC}}{\text { Mean }}$} & \multirow{2}{*}{$\begin{array}{c}\text { Max } \\
\text { time }(\mu \mathrm{s})\end{array}$} \\
\hline & & Minimum & Mean & & \\
\hline EX1 & 13.20 & 0 & 51.36 & 3.89 & 23756 \\
\hline EX2 & 12.75 & 0 & 48.52 & 0.26 & 103080 \\
\hline
\end{tabular}

to develop the multi-objectives algorithm proposed (three loops and six calls to the BSA), the simulation time remains small (a few microseconds). Furthermore, the use of the backtracks option for the BSA algorithm allows a limited increase $(1 \%)$ of allocation coverage. The best results for allocation coverage are obtained for the Simulated Annealing approach with about $70 \%$ coverage. The other algorithms lead to approximately the same allocation coverage of the BSA algorithm. Globally, the lower simulation time is obtained by our approach and the bigger by Simulated Annealing. However, this simulation time remains weak and less than $0.1 \mathrm{~s}$.

The performance of the proposed multi-objective approach remains globally acceptable. However, it is not surprising to observe some bad results. For some objectives, no solutions are found. The multi-objectives satisfaction problem is more difficult to solve (a multidimensional NP-hard problem). Moreover, the iterative use of the Binary Search-based Algorithm adds many times the drawbacks of this approach (a heuristic for treatment order). Furthermore, during the execution of the multi-objectives algorithm, the selection of the greater set of solutions is in fact a heuristic that cannot be always the best one.

\section{Discrimination between non-exact and exhaustive approaches}

Up to now, we have not specified explicitly the condition allowing one to choose to use an exhaustive or an on exact algorithm for the allocation task. In fact, in figure 17, the test 'low complexity problem' depends on many parameters. On the one hand, it depends on the time limit (TL) allowed to find the allocation solutions. This parameter can be fixed by the user. On the other hand, we must now evaluate the time (exhaustive estimate time, EET) needed for an exhaustive approach that will determine all the solutions but needs a large amount of simulations. EET depends on two main factors. The first is the exhaustive number of simulations (ENS). This number is deduced from the enterprise process characteristics (number of activities, number of potential human resource by activity and the process behaviour). The second is the estimated time for a unique simulation (ETUS). This factor depends on the process characteristics but also largely on hard- and software implementation. For example, the exhaustive simulation of EX2 implemented on Matlab software needs more than $10 \mathrm{~s}$. EET can be estimate by multiplying ENS and ETUS. So finally, the exhaustive approach can be used when EET $<$ TL.

From an other point of view, we can also answer the question: What is the limited exhaustive complexity (LEC) corresponding to a fixed limit time? If we consider that a user-friendly software corresponds to a limit time $<1 \mathrm{~s}$, from the results shows in this paper, we can estimated that LEC is approximately equal $5 \times 10^{6}$ possible exhaustive simulations. This great number corresponds in fact to 


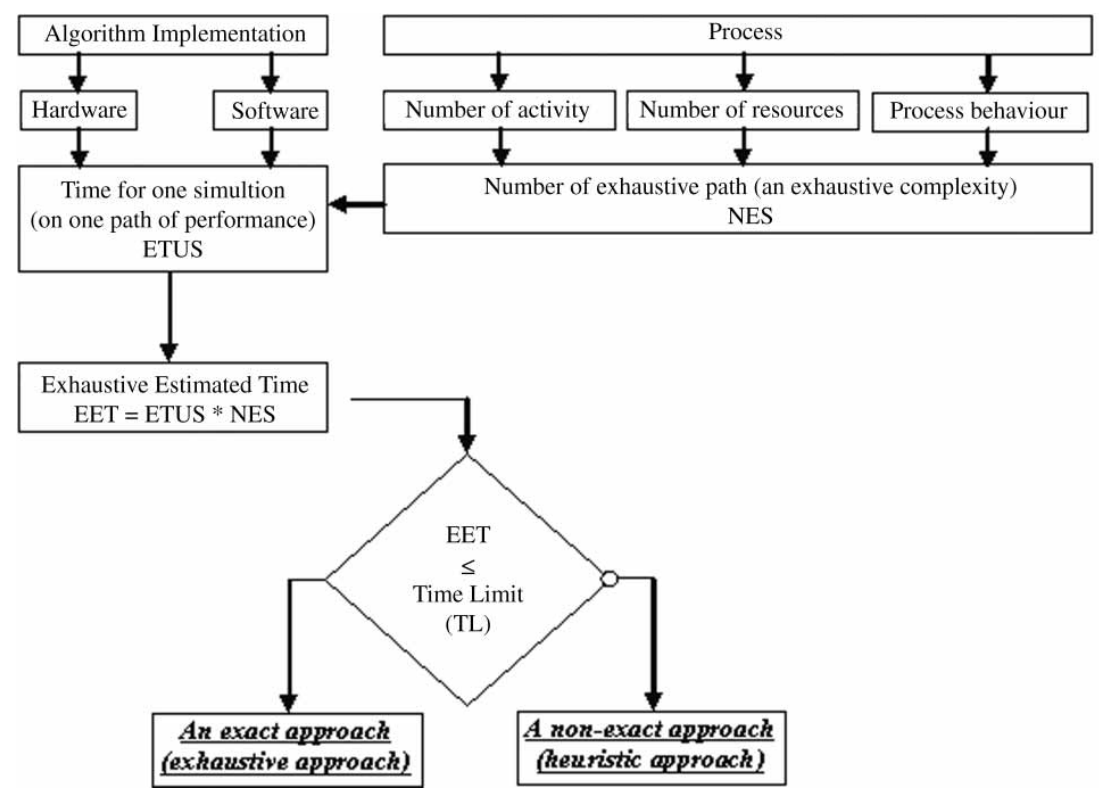

Figure 17. Exhaustive or non-exact approach?

a sequential process with eight activities and seven potential resources by activity. This process seems not to be very complex and must commonly exist in an enterprise.

\section{Conclusion}

This paper focuses on the problem of human allocation to enterprise process activities. Here, the enterprise process can be seen as an ordered set of activities to be executed where no duration is known. Then the fixed goal is to affect the workers, by taking into account their skills, in order to reach one or several enterprise POs.

Among the constraints that would be integrated for human allocation, we consider that the set of workers satisfying the skills required for an activity is known and that they are available. A process performance estimation methodology proposed in an industrial project integrates the workers skills to evaluate activities and process performances.

Then based on these assumptions, we studied limited and large benchmark complexity, different algorithmic approaches that propose, in $<1 \mathrm{~s}$, a set of affectations satisfying the POs.

For a unique PO, the Binary Search-based Algorithm developed and the Simulating Annealing one obtains good results for limited complexity examples. The Pisinger approach looks the worst. On a large complexity example, the performance of the Hybrid Taboo-Descent Algorithm is twice more expensive and Simulated Annealing is better than the BSA. For multi-POs, we have proposed a simple and iterative technique allowing one to detect quickly and for most of the time a large amount of allocation solutions. 
This paper has addressed a few aspects of human allocation concerning the integration of skill to reach one or more POs constraints. Furthermore, it has proposed a heuristic approach based on a BSA to solve the problem of allocation. Most of the time this approach has better results than Simulated Annealing. Moreover, our algorithm is easier to develop and has few parameters to be fixed. Globally the algorithms have an equivalent allocation coverage, but they present a large dispersion on the number of needed simulations. Then, the Pisinger approach has always the best efficiency coefficient despite of its weak allocation coverage.

Future works can focus on the integration of fuzzy performance to take into account a non-deterministic model of the human entity and to explore more sophisticated heuristics for the Binary Search-based approach in order to improve the results observed on large-scale benchmark.

Human Resource Managing is a key point of enterprise performance. It is essential to integrate the skills for process performance evaluation and to propose to the human decider friendly tools to help him drive the processes and detect organizational problems. The development of this kind of approach integrating all the dimensions of the human entities at work, such as competencies, people, flexibility, holidays, laws, etc., in the context of enterprise performance and evolution will be certainly one of the most important challenges of the next few decades.

\section{References}

Alfares, H.K., Dual-based optimization of cyclic four-day workweek scheduling. IMA J. Math. Appl. Bus. Ind., 2000, 11, 269-283.

AMICE, CIMOSA: Open System Architecture for CIM, 2nd revd edn, 1993 (Springer: Berlin).

Aykin, T., A comparative evaluation of modelling approaches to the labour shift scheduling problem. Eur. J. Oper. Res., 2000, 125, 381-397.

Bard, J.F., Binici, C. and Desilva, A.H., Staff scheduling at the United States postal service. Comput. Oper. Res., 2003, 30, 745-771.

Beaumont, N., Scheduling staff using mixed-integer programming. Eur. J. Oper. Res., 1997, 98, 473-484.

Bobrowski, P.M. and Park, P.S., An evaluation of labor assignment rules when workers are not perfectly interchangeable. J. Oper. Manag., 1993, 11, 257-268.

Brusco, M.J. and Jacobs, L.W., Optimal models for meal break and start-time flexibility in continuous tour scheduling. Manag. Sci., 2000, 46, 1630-1641.

Chen, H.G., Heuristic for operator scheduling in group technology cells. Comput. Oper. Res., 1995, 27, 261-276.

Covès, C., Analyse et estimation de performances de processus d'entreprise. $\mathrm{PhD}$ thesis, Université de Montpellier 2, 2000.

Covès, C., Crestani D., Chapurlat, V. and Prunet, F., Implementation of an approach of performance estimation for enterprise process analysis, in MCPL'2000, 2000, Grenoble, France.

Dantzig, G.B., A comment on Edie's traffic delays at tool booths. Oper. Res., 1954, 2 , 339-341.

Drejer, A., How can we define and understand competencies and their development? Technovation, 2001, 21, 135-146.

Eckstein, A.L.H. and Rohleder, T.R., Incorporating human resource in group technology/ cellular manufacturing. Int. J. Prod. Res., 1998, 36, 1199-1222.

Franchini, L., Aide à la décision pour la gestion des opérateurs de production. $\mathrm{PhD}$ thesis, Institut National Polytechnique de Toulouse, 2000.

Franchini, L., Caillaud, E., Nguyen P. and Lacoste, G., Workload control of human resources to improve production management. Int. J. Prod. Res., 2001, 39, 1385-1403. 
Franchini, L., Caillaud, E., Nguyen, P. and Lacoste, G., Planning and scheduling skills: a case study in an agri-food industry, in Proceedings of IEEE Conference of Systems, Man and Cybernetics, 1998, pp. 417-422.

Guest, D.E., Human resource management and performance: a review and research agenda. Int. J. Hum. Res. Manag., 1997, 8, 263-276.

Hao, J., Galinier, P. and Habib, M., Métaheuristiques pour l'optimisation combinatoire et l'affectation sous contraintes. Rev. Intell. Artif., 1999, 13, 283-324.

Hung, R., Scheduling a workforce under annualized hours. Int. J. Prod. Res., 1999, 37, 2419-2497.

Jia, T., Vers une meilleure gestion des performances d'un groupe autonome de fabrication. PhD thesis, Université de Tours, 1998.

Kembel, J., ROLE Play - Personalities in Action, Life Change Partners, 1996 (Northwest Learning Associates, Incorporated: Tucson, Arizona, U.S.A).

Kher, H.V., Malhotra, M.K., Philipoom, P.R. and Fry, T.D., Modeling simultaneous worker learning and forgetting in dual resource constrained systems. Eur. J. Oper. Res., 1999, 115, 158-172.

Kirkpatrick, S., Gelatt, C.D. and Vecchi, M.P., Optimisation by Simulated Annealing. Research Report RC 9355, 1982 (IBM: T.J. Wattson Research Center, Yorktown Heights, New York, U.S.A).

Kolbe, K., Pure Instinct, 1994 (Random House: New York).

Kulanoot, A., Algorithms for some hard knapsack problems. PhD thesis, Curtin University of Technology, 2000.

Kusiak, A. and Chen, M., Expert system for planning and scheduling manufacturing systems. Eur. J. Oper. Res., 1988, 34, 113-130.

Lengnick-Hall, C.A. and Lengnick-Hall, M.L., Strategic human resources management: a review of the literature and a proposed typology. Acad. Manag. Rev., 1988, 13, 454-470.

McCarthy, B.L., Wilson, J.R. and Crawford, S., Human performance in industrial scheduling: a framework for understanding. Hum. Fact. Ergonom. Manuf., 2001, 11, 299-320.

McEwan, A.M. and Sackett, P., The human factor in CIM systems: worker empowerment and control within a high-volume production environment. Comput. Ind., 1998, 36, 39-47.

McKay, K.N., Buzacott, J.A., Charness, N. and Safayeni, F.R., The scheduler's predictive expertise: an interdisciplinary perspective. In Artificial Intelligence In Operational Research, edited by G.I. Doukidis and R.J. Paul, pp. 139-150, 1992 (MacMillan: London).

Medsker, K.L. and Fry, J.P., 1997, Acquisition of interpersonal communication skills; a research-based approach. Telemat. Inform., 1992, 14, 209-218.

Metropolis, N., Rosenbluth, R., Rosenbluth, M., Teller, A. and Teller, E., Equation of state calculations by fast computing machines. J. Chem. Phys., 1953, 21, 1087-1092.

Mosheiov, G., Scheduling problem with a learning effect. Eur. J. Oper. Res., 2001, 132, 687-693.

Narasimhan, R., Algorithm for a multiple shift scheduling of hierarchical workforce on four day or three-day workweeks. INFOR, 2000, 38, 14-32.

Norman, B.A., Tharmmaphornphilas, W., Needy, K.L., Bidanda, B. and Warner, R.C., Worker assignment in cellular manufacturing considering technical an human skill. Int. J. Prod. Res., 2002, 40, 1479-1492.

Papadimitrou, C.H. and Steiglitz, K., Combinatorial Optimization: Algorithms and Complexity, 1982 (Prentice-Hall: Englewood Cliffs, NJ).

Parsons, D.O., Specific human capital: an application to quits rates and layoff rates. J. Polit. Econ., 1972, 80, 1120-1143.

Pisinger, D., A minimal algorithm for the multiple-choice knapsack problem. Eur. J. Oper. Res., 1995b, 83, 394-410.

Pisinger, D., Algorithms for knapsack problems. PhD thesis, University of Copenhagen, 1995a.

Saaty, T.L., The Analytical Hierarchy Process, 1980 (McGraw Hill: New York).

Soubeiga, E., Development and application of hyperheuristics to personnel scheduling. PhD thesis, University of Nottingham, 2003. 
Tchommo, J.L., Baptiste, P. and Soumis, F., Etude bibliographique de l'ordonnancement simultané des moyens de production et des ressources humaines, in Proceedings of the 5th French-Quebec International Congress of Industrial Engineering, Quebec, Canada, 2003.

UEML, the strategy for UEML, WP.3, Project UEML, deliverable 1 March 2003.

Vairaktarakis, G.L., Cai, X. and Lee, C.Y., Workforce planning in synchronous production systems. Eur. J. Oper. Res., 2002, 136, 551-572.

Williams, T.J., Development of GERAM, a Generic Enterprise Reference Architecture and Enterprise Integration Methodology. In Integrated Manufacturing Systems Engineering, edited by P. Ladet and F.B. Vernadat, pp. 279-288, 1995 (Chapman \& Hall: Chichester).

Williams, T.J., The Purdue Enterprise Reference Architecture. Comput. Ind., 1994, 24, $141-158$.

Wright, P. and Snell, S., Toward an integrative view of strategic human resource management. Hum. Manag. Res. Rev., 1991, 1, 203-225. 